\title{
A internacionalização de empresas na agenda governamental contemporânea de desenvolvimento: reflexões críticas e analíticas para os negócios internacionais
}

\author{
Diego Bonaldo CoELHO \\ Escola Superior de Propaganda e Marketing (ESPM), SÃo Paulo- SP, Brasil \\ MOACIR DE MIRANDA OLIVEIRA JUNIOR \\ Universidade de SÃo Paulo / FACUldade de ECONOMIA, AdMINISTRAÇÃo E CONTABILIDAde (FEA/USP), \\ SÃO PAULO- SP, BRASIL
}

\begin{abstract}
Resumo
Na forma de ensaio, este artigo reflete sobre o fenômeno da internacionalização como um mediador das relações entre governos e empresas em contexto de ampla competição internacional, dada uma realidade econômica global. Analisa-se, dessa forma, que a internacionalização das empresas, pelas suas características e externalidades, passa a ser incorporada como problema público nas agendas governamentais de políticas públicas, sendo objeto de incentivo, apoio e indução. Suscitam-se, assim, fatores que historicamente sustentam essa afirmação, da mesma forma que se sugere a construção de um referencial teórico de identificação e análise desse tipo específico de política. As conclusões são fundamentadas na defesa de que tais políticas, atualmente uma tendência, devem ser tratadas como uma nova variável para pensar as estratégias empresariais e nacionais de desenvolvimento, cujas implicações teóricas e empíricas podem levar a releituras, tanto das abordagens predominantes da internacionalização (como o Paradigma Eclético de Dunning e a Escola de Uppsala) quanto dos ciclos de políticas públicas, com destaque para seus conflitos, objetivos e benefícios. Com isso, demanda-se uma nova frente de pesquisa sobre o tema, particularmente nos países em desenvolvimento.
\end{abstract}

Palavras-chave: Políticas públicas. Internacionalização de empresas. Economia global.

Internationalization of companies in the contemporary government development agenda: critical and analytical reflections for international business

\begin{abstract}
As an essay, this article thinks through the internationalization phenomenon as a mediator in the relations between governments and companies in a context of wide international competition, given a global economic reality. Thus, this article argues that the internationalization of companies, due to its characteristics and externalities, becomes incorporated as a public problem in the governmental agendas, and it is an object of incentive, support, and induction. So, this article raises factors that support this claim on a historical basis, and it also suggests the development of a theoretical framework for identifying and analyzing this particular kind of policy. The conclusions are grounded in advocating that such policies, currently a tendency, must be addressed as a new variable to think of the business and national development strategies, whose theoretical and empirical implications may lead to rereadings both of the predominant approaches to internationalization (such as Dunning's Eclectic Paradigm and the Uppsala School) and the public policy cycles, where their conflicts, goals, and benefits stand out. Thus, there emerges a new research line on the theme, particularly in developing countries.
\end{abstract}

Keywords: Public policies. Internationalization of companies. Global economy.

La internacionalización de empresas en la agenda gubernamental contemporánea de desarrollo: reflexiones críticas y analíticas para los negocios internacionales

\section{Resumen}

Con el formato de ensayo, este artículo refleja acerca del fenómeno de la internacionalización como un mediador de las relaciones entre gobiernos y empresas en contexto de amplia competencia internacional, en el marco de una realidad económica global. Así, se analiza que la internacionalización de empresas, por sus características y externalidades, se incorpora como un problema público en las agendas gubernamentales de políticas públicas, siendo objeto de incentivo, apoyo e inducción. Se plantean, por lo tanto, factores que históricamente sostienen dicha afirmación, de la misma manera que se sugiere la construcción de un referencial teórico de identificación y análisis de este tipo específico de política. Las conclusiones se fundamentan en la defensa de que dichas políticas, una tendencia actual, se deben tratar como una nueva variable para pensar las estrategias empresariales y nacionales de desarrollo, cuyas implicaciones teóricas y empíricas pueden llevar a relecturas, tanto de los abordajes predominantes de la internacionalización (como el Paradigma Ecléctico de Dunning y la Escuela de Uppsala), como de los ciclos de políticas públicas, destacando sus conflictos, objetivos y beneficios. Con esto, se requiere un nuevo frente de investigación sobre el tema, especialmente en los países en vía de desarrollo.

Palabras clave: Políticas públicas. Internacionalización de empresas. Economía global. 


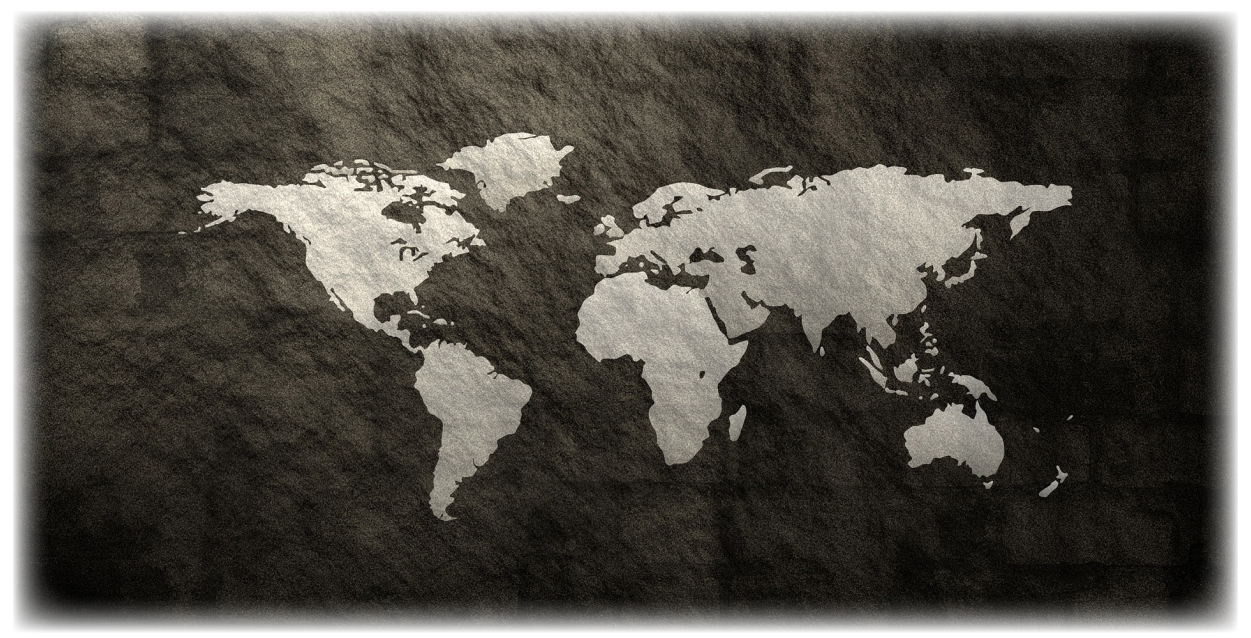

\section{INTRODUÇÃO}

A expansão do fenômeno da globalização, ao tornar nosso planeta um espaço potencialmente integrado, culminou na emergência de um novo contexto histórico, com impactos e modificações em todas as esferas da vida humana. Na economia, em particular, a possibilidade de organizar as atividades econômicas e suas componentes em escala mundial permitiu a formação de nova realidade, a economia global, que revolucionou as determinantes da competição e do crescimento econômico (CASTELLS, 1999). Nessa nova economia, os paradigmas são outros. Inúmeras e extraordinárias oportunidades são vislumbradas na mesma proporção em que se defrontam inéditos e complexos desafios. Se por um lado, a Terceira Revolução Industrial, as reformas institucionais de governança global iniciadas no pós-Segunda Guerra - tais como o Fundo Monetário Internacional (FMI), o Banco Mundial e a consolidação de um Sistema Multilateral de Comércio (OMC/GATT) - e o predomínio das tendências de políticas mais liberalizantes e de integração regional da década de 1990 proveram novas bases materiais tecnológicas para os transportes, telecomunicações e informática facilitadoras de logística e dos negócios, bem como novos e mais acessíveis mercados e maior grau de mobilidade de fatores de produção e ativos financeiros, por outro, os seus inevitáveis corolários, como o forte acirramento da concorrência, a intensificação das incertezas, riscos, ameaças e crises, impuseram e demandaram substanciais modificações no comportamento estratégico das empresas e dos governos.

As empresas, para incrementarem as suas curvas de lucratividade diante da concorrência e das turbulências, iniciaram a expansão de suas atividades e operações das mais diversas formas, focadas, sobretudo, na reinvenção de estratégias capazes de promover ganhos de produtividade e competitividade. A mera busca por clientes domésticos, ou a redução dos custos de produção via racionalização dos processos de trabalho e substituição de insumos, matérias-primas e fornecedores internos, marcantes de épocas passadas, ainda que importantes, não são mais as determinantes de impacto da nova realidade contemporânea. No contexto da economia global, as empresas adotam estratégias mais complexas, sofisticadas e ousadas para consecução de seus fins, as quais reascendem a relevância de suas estruturas e fronteiras organizacionais (CHANDLER JR., 2001; BUCKLEY e CASSON, 2002; WILLIAMSON, 1991), o desenvolvimento e aquisição de competências informacionais e gerenciais (PENROSE, 2006; CASTELLS, 1999), a tecnologia e inovação (KUMPE e BOLWIJN, 1994; PENROSE, 2006), e, destacadamente, a atuação internacional (CHANDLER JR., 2001; DICKEN, 2010; BUCKLEY, 2002).

Desse modo, a dimensão internacional se tornou cada vez mais presente no âmbito empresarial. $O$ avanço e a inserção das empresas no exterior tornaram-se a opção estratégica predominante do novo século, inclusive à própria manutenção e sobrevivência no mercado doméstico (BUCKLEY e CASSON, 2002; DUNNING e LUNDAN, 2008). A internacionalização das empresas

\footnotetext{
* Fonte da imagem: CCO Public Domain.
} 
passou a ser uma tendência inevitável (RICUPERO e BARRETO, 2007), uma condição indispensável para o sucesso e sobrevivência empresariais (MAJOCCHI, BACCHIOCCHI e MAYRHOFER, 2005), corroborada nas últimas décadas por quatro aspectos inter-relacionados: i) crescimento substancial do comércio internacional; ii) aumento do investimento direto estrangeiro; iii) papel central das empresas multinacionais como produtoras na economia global; e iv) formação de redes internacionais de produção. (CASTELLS, 1999; DICKEN, 2010).

Nesse contexto - embora exista a defesa hiperglobalista (OHMAE, 1990) de que no devir da globalização os Estados se tornaram insignificantes e as empresas multinacionais passaram a determinar os rumos dos negócios e da economia independentemente dos governos, os quais teriam ficado condenados à posição de reféns da situação - uma importante frente de pesquisa, bem representada por autores como Porter (1989), Castells (1999), Stopford (2003) e Dicken (2010), sustenta que o Estado está vivo e presente, sendo ator relevante no jogo internacional, além de desempenhar papel fundamental no desenvolvimento econômico de todos os países. Para essa vertente, não tem aderência histórica contemporânea a noção hiperglobalista de que a globalização e a economia global formaram um mundo plano, sem fronteiras, no qual as empresas multinacionais são as únicas fontes de poder e a questão nacional não é mais relevante, com os Estados perdendo sua importância na geografia econômica mundial e, os governos, os destinos de suas economias (YEUNG, 1998; DICKEN, 2010; CASTELLS, 1999; GILPIN, 2001; STOPFORD, 1999; PORTER, 1989; RODRIK, 2004; VERNON, 1998; BRESSER-PEREIRA, 2009; VIETOR, 2007). Pelo contrário, embora a globalização da competição dê a falsa aparência de que o Estado seja menos essencial, o fato é outro: tornou-se ainda mais importante (PORTER, 1989).

A análise encontra respaldo em Kelly (1999), especialmente na interpretação de que os Estados seguem trajetórias diferentes ao longo da história, mas que continuam sendo ativamente construídas, fortalecidas e expandidas, em vez de enfraquecidas. Torna-se difícil decretar sua derrocada no mundo hodierno, sendo mais provável a constatação da revisão de seu protagonismo, formas e limites de atuação. Processo que, para Vietor (2007), não apenas está em curso, como tem ocorrido a partir das novas características e complexidade da economia global, encontrando na competição seu principal direcionador. Para esse autor, o acirramento da concorrência em âmbito mundial extrapolou o campo e as dinâmicas empresariais e alcançou os países, pressionando os Estados a incorporarem sua lógica: passam a contender por mercados, empreendimentos, recursos e tecnologias capazes de impulsionar e sustentar o crescimento de suas economias (VIETOR, 2007).

Nesses termos, conforma-se uma realidade econômica que, pautada pela lógica da competição internacional, tornou a interdependência entre empresas e governos mais evidente, compelindo estes atores a requalificar as suas relações e interações a partir da constatação de que seus desempenhos estão consideravelmente vinculados (PORTER, 1986; 1989; DUNNING, 1997) e mediados por interesses mútuos. Nesta linha de raciocínio, Castells (1999) e Dicken (2010) defendem que os governos devem incorporar a função de formular e levar a cabo políticas para promover o desempenho de empresas em suas economias, desenvolvendo estratégias em nome de seu empresariado. Pois, como argumentou Porter (1989), tomadas as empresas como as verdadeiras unidades dinamizadoras das economias, a robustez do crescimento nacional passa necessariamente pela capacidade de o Estado catalisar e induzir a competitividade dos empreendimentos presentes em seu território, particularmente a construção de ambiente e condições favoráveis à internacionalização, como destacaram Vietor (2007) e Dunning (1997).

Não por acaso, para Boddewyn (1992), o devir da realidade econômica global tem marcado a evolução das relações governoempresas de uma situação de conflito e restrições para uma nova era de cooperação. A questão se destaca nas estratégias internacionais empresariais, com a constatação de que diversos governos passaram a reconhecer seu vínculo com a internacionalização das empresas, optando pela sua cooperação e seu incentivo (VERNON, 1998; STOPFORD, STRANGE e HENLEY, 1991; DICKEN, 2010; STRANGE, 1994; 2000; GROSSE, 2005; VIETOR, 2007). Por conseguinte, uma grande problematização acerca do papel dos governos na internacionalização das empresas é colocada, na qual se destaca a legitimidade, formas e impactos das políticas governamentais destinadas à expansão internacional de empresas nacionais. Tema que é endossado e decorrente do fato de a majoritária parte dos países ter optado recentemente por adotar políticas públicas específicas como ações para incrementar a competitividade de empresas de suas economias, incentivando e apoiando os seus processos de internacionalização (UNCTAD, 2005; 2006; 2008; BARRAL, 2011; IPEA, 2012).

Diante de tais eventos, pensar as empresas com atuação internacional e suas relações com os governos tornou-se a pauta organizacional, econômica e política do novo tempo (GUEDES, 2006), que inaugura nova agenda de pesquisa da Ciência Política, Economia, Administração e Negócios Internacionais, interessada, acima de tudo, em refletir os modos pelos quais 
estes atores se relacionam e lidam com suas respectivas complexidades na realidade contemporânea da economia global. Nesse contexto e termos, pretende-se, no presente artigo, lançar luz sobre a incorporação do fenômeno da internacionalização à agenda governamental, com vistas a problematizar alguns de seus pontos críticos e essenciais. Busca-se refletir, criticamente, na forma de ensaio, a tomada da internacionalização das empresas como um problema público específico da agenda governamental (agenda setting) de políticas públicas, que passa a ser tomada, cada vez mais, principalmente em países emergentes, como um fenômeno de preocupação dos formuladores de políticas (policymakers), ensejando ações e instrumentos direcionados ao seu incentivo, indução e suporte.

Para consecução desses fins analíticos, este ensaio está organizado da seguinte maneira: primeiramente, será analisado como a questão da internacionalização, considerada como um fenômeno empresarial típico da realidade econômica global, passa a ser assumida como um problema público, passível de ser incorporada pela agenda governamental. Em seguida, ao observar a maneira pela qual os governos tendem a tratar o fenômeno, investiga-se se este passa a ser interpretado no que Kingdon (2003) sugeriu se tratar de uma agenda de políticas governamentais (policy agenda-setting), com as suas questões sendo tratadas, de fato, pelos formuladores de políticas públicas. Nessa oportunidade, será proposto, para fins analíticos, algumas dimensões que podem ser consideradas para os estudos de políticas governamentais direcionadas à internacionalização, constituindo-se em referencial pertinente para identificação de seus instrumentos, análises e inferências, inclusive entre países (cross-countries). Por fim, suscita-se debate acerca da pertinência aos estudos da área de Negócios Internacionais em assumir a possibilidade da tomada da internacionalização de empresas como um problema e objeto de políticas governamentais, momento em que são destacados os seus potenciais e principais impactos analíticos e empíricos. As motivações das conclusões ensejadas pautam-se, fundamentalmente, tanto na defesa de que as políticas governamentais de apoio de internacionalização devam ser incorporadas como relevante dimensão da análise da inserção empresarial internacional, quanto na sugestão de que, para estes fins de pesquisa, o referencial teórico constituído seja pertinente e útil para estudos futuros.

\section{GOVERNOS E EMPRESAS NO CONTEXTO DA ECONOMIA GLOBAL: A TOMADA DA INTERNACIONALIZAÇÃO COMO UM PROBLEMA PÚBLICO}

A consolidação de uma realidade econômica global a partir dos resultados da Terceira Revolução Industrial e da intensificação do processo de globalização (CASTELLS, 1999), no esteio das reconfigurações econômicas e de poder do sistema internacional pós-Segunda Guerra e pós-Guerra Fria, impuseram novas agendas nacionais e internacionais, tanto para as empresas quanto aos Estados. Como observaram Stopford, Strange e Henley (1991, p. 4), "a mudança estrutural na economia política internacional alterou a natureza do jogo, afetando as ações e reações entre as empresas e estados". Atualmente, estas são, em grande parte, constituídas diante de uma situação na qual não apenas as empresas acirram a concorrência entre si em âmbito mundial, optando pela internacionalização como sua estratégia mais típica (RICUPERO e BARRETO, 2007; MAJOCCHI, BACCHIOCCHI e MAYRHOFER, 2005), mas em que os Estados, por meio de seus governos, passaram a disputar espaço, e principalmente recursos estratégicos capazes de proverem competitividade nacional (CASTELLS, 1999; PORTER, 1986; 1989).

Inevitavelmente, as relações entre governos e empresas são requalificadas, quer por parte governamental quer empresarial, tendo por seu novo marca-passo o fato de que agora as rivalidades entre governos, de um lado, e entre empresas, de outro, estimuladas pela busca de lugar seguro na economia global, adquiriram força, tornaram-se mais intensas, abrindo uma nova fronteira interorganizacional em que as empresas ficaram mais envolvidas com os governos e estes reconhecem que aumentaram sua dependência dos recursos estratégicos e escassos controlados por elas (STOPFORD, STRANGE e HENLEY, 1991). Novas frentes e dinâmicas entre governos e empresas são então constituídas, uma vez que no contexto em que os negócios empresariais tendem a ser internacionais, sua ocorrência necessária e minimamente envolverá o relacionamento com dois governos (GROSSE, 2005), o de origem (home government) e o de destino (host government). O que repercutirá não somente no desempenho das empresas, mas em aspectos de desenvolvimento dos países.

A lógica que sustenta tais afirmações parte do entendimento de que as empresas, ao internacionalizarem as suas atividades e operações, passam a integrar políticas de preço e produção, controlar ativos específicos (capital, tecnologia, capacidades gerenciais, organizacionais e mercadológicas) e canais de distribuição internacionalmente (HYMER, 1983), os quais determinam, em grande parte, questões pertinentes ao crescimento econômico dos países, tais como comércio internacional, 
movimentação de fatores, fluxos financeiros, difusão do progresso técnico e alocação de recursos (HYMER, 1983; GILPIN, 2001; DUNNING e LUNDAN, 2008; CAVES, 1996; DICKEN, 2010). Ou seja, fatores que motivam e justificam os interesses dos governos, sejam eles de origem ou destino.

Por conseguinte, interações necessárias e irreversíveis entre governos e empresas são formadas, as quais, de acordo com Grosse (2005), podem resultar em conflitos ou alinhamentos entre as políticas de dois governos ou entre governos e empresas, que, motivados por diferenças de interesses, acabam por demandar toda a sorte de mediações. Entre elas, destaca-se a emergência do modelo de diplomacia triangular, caracterizado por interações e relações em três níveis: governo-governo, governo-empresas e empresas-empresas, pautados por barganhas a partir de interesses político-econômicos interdependentes entre estes atores (STOPFORD, STRANGE e HENLEY, 1991; STRANGE, 1994; 2000).

Historicamente, esse novo cenário pode ser apreendido pela análise das modificações ocorridas na forma e no conteúdo dos relacionamentos estabelecidos entre os governos e as empresas ao longo do século XX. Até meados dos anos 1960, como relatou Grosse (2005), as relações entre governos e empresas eram destacadamente conflituosas, principalmente no que concernia à internacionalização dos negócios. Em particular, havia a relutância de muitos governos de destino em permitir o ingresso de empresas estrangeiras em suas economias nacionais, com opção por vezes deliberada de impor fortes restrições às suas operações (GROSSE, 2005). De acordo com Dunning (1998), essa tensão se estendeu até os anos 1970, quando, não ocasionalmente, se explodia em confronto direto, o que culminava em expropriação ou nacionalização de ativos estrangeiros.

Entretanto, esse perfil é alterado no último quarto daquele século. Houve uma guinada perceptível no teor, nos objetivos e na condução das relações entre governos e empresas no contexto da economia global, atingindo uma dinâmica mais cooperativa, construtiva e transigente entre as partes (BODDEWYN, 1992; DUNNING, 1998). As suas justificativas se resguardaram, como argumentado por Porter (1989), Dunning (1997), Dicken (2010) e Strange (1994), na necessidade imposta aos governos de reconhecer sua forte interdependência com as empresas, requalificando as suas interações a partir da constatação de que os seus desempenhos estão consideravelmente vinculados e mediados por interesses mútuos, ainda que por vezes conflituosos. Na análise de Vietor (2007), essa motivação, praticamente uma imposição contemporânea, decorreu da situação observada na nova economia de que a competição internacional extrapolou o campo e as dinâmicas empresariais e alcançou os Estados, o que pressionou os governos a incorporarem sua lógica: contender por mercados, empreendimentos, recursos e tecnologias capazes de impulsionar e sustentar o crescimento e desenvolvimento de suas economias.

Nessa linha de raciocínio, as empresas não deixam de ser entendidas e consideradas como as principais dinamizadoras das economias nacionais (PORTER, 1989; DUNNING, 1997). Todavia, tendo em vista as novas dinâmicas alocativas propiciadas pela globalização, bem como a abrangência e acirramento da concorrência em escala global, os impactos e externalidades gerados pelas atividades econômicas empresariais tornam-se geograficamente dispersos. Desse modo, os governos são atores relevantes não apenas na determinação desse processo, mas interessados em maximizar seus ganhos a partir dele, seja como origem e/ou destino. Não por acaso, autores como Castells (1999) e Dicken (2010), por exemplo, passaram a defender que os governos diante dessa nova realidade devem incorporar a função de formular e levar a cabo políticas para promover o desempenho das empresas em suas economias, desenvolvendo estratégias em nome de seu empresariado. Para Castells (1999) tal processo configura uma repolitização do capitalismo, o que acaba por ligar, conforme defendido por Carnoy, Manuel, Stephen et al. (1996), os interesses políticos do Estado diretamente ao destino da concorrência econômica das empresas genuinamente nacionais ou em seu território.

O entendimento dado por essa perspectiva de análise é o de que a robustez do crescimento nacional passa necessariamente pela capacidade do Estado em catalisar e induzir a competividade dos empreendimentos presentes em seu território (PORTER, 1989; CASTELLS, 1999; DICKEN, 2010; CARNOY, MANUEL, STEPHEN et al., 1996). Em outras palavras, impõe-se que na lógica da nova economia global, os Estados,

[...] se quiserem aumentar a riqueza e o poder [...] têm que adentrar na arena da concorrência internacional, direcionando as suas políticas para o aumento da competitividade coletiva das empresas sob sua jurisdição, bem como da qualidade dos fatores de produção em seus territórios (CASTELLS, 1999, p. 107).

Nota-se que essa análise vincula a ideia de que a competitividade de uma empresa, principalmente as vantagens que a permitem enfrentar a concorrência global via internacionalização, é em grande parte uma consequência de sua economia doméstica. 
Ou seja, a despeito de uma lógica global de competição e da possibilidade da internacionalização das atividades e operações organizacionais, as empresas são antes e primeiramente arraigadas e baseadas em suas nações (nation-based) (SALLY, 1994; 2000). Trata-se, assim, de ótica cujo argumento se sustenta, conforme Gilpin (2001), na constatação de que, excluídas raras exceções, a majoritária parte das empresas ainda possui os mercados domésticos como os seus primeiros mercados, sendo as políticas governamentais nacionais as que possuem maior peso e influência nas tomadas de decisões empresariais vis-à-vis aquelas promovidas pelos países de destinos. As empresas, nesse sentido, têm sua robustez competitiva consideravelmente desenvolvida a partir de sua nação de origem, cujas características passam a ser consideradas como certa precondição de suas vantagens específicas, sendo o governo nacional responsável pelo ambiente e condições de fatores propícios ou não para a expansão e a performance empresariais nas arenas globais.

Dessa forma, não se tornou inesperada, tampouco imprevisível para essa vertente, a intensificação do debate acerca do papel dos governos nas economias nacionais, o que atualmente parece ocupar espaço central na agenda político-econômica internacional. Na verdade, a principal expectativa observada na literatura econômica e de política econômica internacional, na medida em que esta questão se tornou mais pertinente, era a de direcionar esforços para se apreender e inferir a maneira pela qual as políticas governamentais seriam relidas e incorporariam os novos elementos incutidos pela realidade contemporânea, particularmente os negócios internacionais. Afinal, não é exclusivo da nova realidade o debate sobre as perspectivas e prescrições dos modos e maneiras de realizar ou não intervenções governamentais na economia nacional. O conteúdo dessa discussão remonta o final do século XIX e desde então é basicamente entremeado pela dicotomia entre os oportuna e posteriormente denominados ortodoxos versus heterodoxos (RUBIO, 2012). Porém, não obstante ainda seja uma contenda fortemente arraigada nas fundamentações das políticas macroeconômicas mais tradicionais, é fato que desde os anos 1950 as suas formas, conteúdos e, principalmente, objetivos vêm ganhando outros contornos no esteio da economia global, na qual se destaca essa emergente problemática da competitividade nacional em meio a um contexto de competição global.

Atualmente, a discussão sobre as intervenções do Estado na economia nacional por meio de políticas governamentais alcança outras vertentes, em que, a despeito do peso ainda considerável das políticas macroeconômicas mais típicas, como as cambiais, monetárias e fiscais, outras pautas se tornam mais presentes. Um exemplo são as políticas comerciais, cuja consolidação do Sistema Multilateral de Comércio (OMC/GATT) vem ocupando lugar privilegiado e maior grau de complexidade - afastando-se dos preceitos mercantilistas, além da retomada do papel das políticas industriais e tecnológicas para o desenvolvimento. No seio destas somam-se ainda, mais recentemente, aquelas voltadas para internacionalização de empresas. Nesse processo, uma nova forma de atuação governamental parece se organizar, que, de acordo com Castells (1999, p. 107),

[...] une, em uma estratégia explícita, a competitividade, a produtividade e a tecnologia [em um] novo Estado desenvolvimentista [que] apoia o desenvolvimento tecnológico das indústrias do país e de sua infraestrutura de produção como forma de promover a produtividade e ajudar 'suas' empresas a competir no mercado internacional.

O que, na avaliação de outros autores, como Musacchio e Lazzarini (2013), trata-se da conformação de um modelo emergente de capitalismo de Estado.

A sinalização dada pelos governos de vários países parece corroborar a vertente analítica dos autores suscitados. Desde o final do século XX é possível constatar que os governos têm optado por assumir papéis mais ativos nos processos de desenvolvimento de suas economias. Nesse contexto, assiste-se a dinâmicas basicamente fundamentadas na linha descrita por Castells (1999), ocorridas por meio da reformulação de políticas governamentais, agora bem empenhadas e focadas no estímulo à competitividade do território e das empresas ali instaladas, o que Porter (1989) cunhou como a promoção das vantagens competitivas das nações. Portanto, torna-se importante ressaltar que, ainda que o debate sobre as estratégias de desenvolvimento e do papel dos Estados em seu processo tenham assumido contornos e verve fortemente liberais como seu mainstream ao longo da virada do século XX para o XXI, em que se destaca o marco do Consenso de Washington, não se perdeu de vista a revisão e reconsiderações sobre políticas mais dirigistas e intervencionistas (PACK e SAGGI, 2006). Os exemplos mais notórios que têm revelado, por contraste, movimentos nessa direção são os tigres asiáticos de primeira e segunda geração e recentemente a China e a Índia (BAILEY, LENIHAN e SINGH, 2009; NOLAN, 2001; IEDI, 2013). O Brasil ingressa na lista como caso hodierno (SUZIGAN e FURTADO, 2006; LEVY, NONNENBERG e COSTA, 2008; IEDI, 2013). 
Nota-se, nesse sentido, o surgimento de um debate que extrapola a mera questão das políticas macroeconômicas de estabilização mais tradicionais e adentra pela seara de políticas de impactos mais estruturais, capazes de compor articulação em torno de uma estratégia nacional de desenvolvimento (BRESSER-PEREIRA, 2009). Observa-se no bojo desses movimentos, tanto em seu âmbito nacional quanto internacional, a intensificação de políticas tecnológicas para fortalecimento de Sistemas Nacionais de Inovação (SBRAGIA et al., 2006; SOETE, 2007) e a retomada das políticas industriais (RODRIK, 2004; AIGINGER, 2007). Além disso, verificam-se as melhorias das vantagens de localização dos territórios, por meio de ambiente de negócios que comporte infraestrutura, competências, qualificação, carga tributária, câmbio, juros e instituições que sejam atrativas e indutoras das atividades econômicas. Nessas últimas, a competitividade de empreendimentos parece ser central e a relação entre governos e empresas mais próximas e interdependentes, cujos objetivos parecem se revelar mais bem alinhados.

Com essa tendência, como argumentou Porter (1986), não tardou muito para que as políticas direcionadas às indústrias e às relações econômicas internacionais se tornassem as linhas de frente das agendas governamentais, as quais passaram a internalizar, de maneira mais clara e específica, as dinâmicas da internacionalização das empresas no marco estratégico da competitividade e competição internacionais. No tema dos negócios internacionais, especificamente, essa orientação não apenas é perceptível, mas verificada por diversos autores, tais como Vernon (1998), Stopford, Strange e Henley (1991), Dicken (2010), Strange (1994; 2000), Grosse (2005), Vietor (2007), Guedes (2006) e Bazuchi, Zacharias, Broering et al. (2013), cujos estudos revelam que os governos passaram a reconhecer seu vínculo com a internacionalização, optando pela sua cooperação e incentivo. Nesse toar, os esforços governamentais são direcionados, em grande parte das vezes, à construção de ambiente e condições favoráveis à internacionalização, como bem apontaram UNCTAD (2006), Além e Madeira (2010), Barral (2011) e IEDI (2013). A melhor representação desse fenômeno se resguarda na constatação de que, atualmente, governos de vários países começaram a adotar políticas públicas específicas como ações para incrementar a competitividade de suas empresas internacionalmente, apoiando os seus processos de internacionalização (UNCTAD, 2005; 2006; 2008; ALÉM e MADEIRA, 2010; ALÉM e CAVALCANTI, 2005; BARRAL, 2011; SENNES e MENDES, 2009; ACIOLY, LIMA e RIBERO, 2011; WANG, HONG, KAFOUROS et al., 2012; IPEA, 2012; IEDI, 2013). Como ressaltou um dos documentos do IEDI (2013) sobre o assunto,

[...] a ação dos Estados Nacionais na defesa da 'competitividade' de suas empresas tornou-se de tal modo predominante, que os governos não hesitam em distribuir incentivos com o propósito de flexionar musculatura das empresas nacionais e torná-las capazes de dar combate dentro e fora do território nacional.

Por meio dessa vertente de análise, é possível concluir que a repolitização da economia global estimulou ou compeliu os governos a considerar que as verdadeiras unidades dinamizadoras das economias nacionais são as empresas, não os países (PORTER, 1989; DUNNING, 1997). Tal repolitização pode ser pensada na esteira de Castells (1999), que a abordou como uma decorrência da constatação de que o emergente contexto de integração e competição não se trata única e exclusivamente de uma questão empresarial, mas de um processo que repercute no posicionamento das economias nacionais no sistema internacional, como também corroborado posteriormente por Vietor (2007). Nesses termos, prover a competitividade internacional das empresas em seu território se torna um fator-chave na disputa de poder e prosperidade do novo jogo internacional, uma vez que elas estão, conforme Sally (1994; 2000), antes e primeiramente arraigadas em sua nação de origem.

Por conseguinte, diante de uma dinâmica de competição global em que a internacionalização é dimensão relevante (PORTER, 1989; CASTELLS, 1999; DICKEN, 2010; CARNOY, MANUEL, STEPHEN et al., 1996; IEDI, 2013), uma nova fronteira de relação entre os governos e as empresas parece emergir. A qual está predominantemente pautada pela cooperação e transigência na agenda de negócios internacionais em detrimento da exclusividade do conflito (BODDEWYN, 1992; DUNNING, 1998). Como atentou Barral (2011, p. 9), já é possível observar em vários países "a existência de políticas públicas, mais ou menos intervencionistas, de incentivos para o processo de internacionalização", que, não obstante a grande diversidade, eficiência e condições políticas entre si, apresentam em comum o fato de existir "a compreensão de que o processo de internacionalização é um mecanismo para melhor inserção de empresas nacionais e, em última instância, de fortalecimento do próprio poder nacional". Em outras palavras, a internacionalização de empresas, ao que tudo indica, parece ser incorporada à agenda governamental como um problema público contemporâneo. 


\section{POLÍTICAS GOVERNAMENTAIS DE APOIO À INTERNACIONALIZAÇÃO: PROPOSTA DE FRAMEWORK DE SUA NATUREZA, ESCOPO E DIMENSÕES ANALÍTICAS}

Discutir o apoio e o suporte de governos aos negócios internacionais, em particular à internacionalização das empresas, tem como um de seus caminhos possíveis a ótica das políticas governamentais, em tema que se encontra situado no âmago do debate sobre políticas públicas. Embora desde os anos 1930 as políticas públicas venham se constituindo como seara própria e interdisciplinar de reflexão, reconhecida atualmente na literatura como estudos de políticas públicas (policy studies) (SOUZA, 2006; NAGEL, 2002; HOWLETT, RAMESH e PERL, 2013), os seus marcos teóricos mais relevantes foram desenvolvidos no âmbito das Ciências Políticas, como apontado por Ham e Hill (1984). No entanto, não obstante sua delimitação temática ao longo do tempo, seu intenso diálogo com as Ciências Políticas e sua crescente produção nos últimos anos, ainda não há consenso bem sedimentado e comum em sua literatura em torno de uma definição que seja definitiva para as políticas denominadas governamentais. De toda maneira, é possível pacificar a questão ao considerá-las, no contexto das políticas públicas, como um de seus tipos específicos, de natureza, formulação, dinâmica e escopo particulares. Afinal, mesmo que alguns autores tratem as políticas públicas e governamentais como sinônimos e conceitos intercambiáveis, os termos são passíveis de distinção (SOUZA, 2006; HEIDEMANN, 2009). Pois, como destacou Heidemann (2009, p. 31), "a perspectiva de política pública vai além da perspectiva de políticas governamentais, na medida em que o governo, com sua estrutura administrativa, não é a única instituição a servir à comunidade política, isto é, a promover 'políticas públicas'”. Dessa forma, assumindo-se a ideia abrangente de políticas públicas como as diretrizes elaboradas para enfrentar um problema público, as políticas governamentais adquirem status e natureza de seu tipo particular, entendidas como aquelas que são formuladas e estabelecidas por atores governamentais, tornando-se, assim, um de seus subgrupos, como ilustrado na Figura 1 (SECCHI, 2013).

Figura 1

Políticas públicas e políticas governamentais

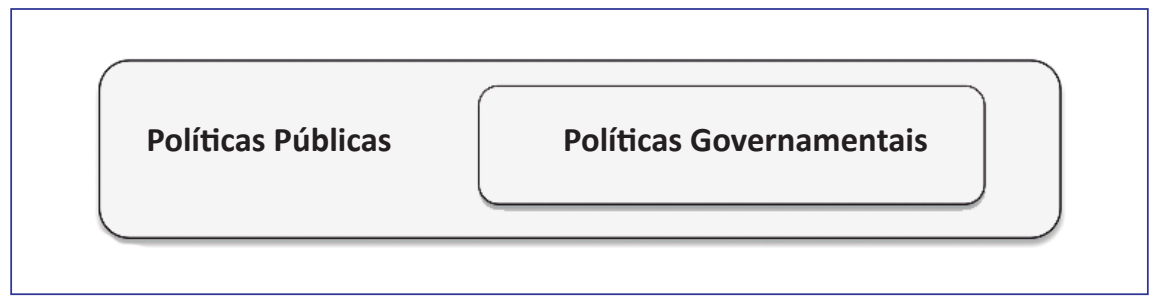

Fonte: Elaborado a partir de Secchi (2013).

Estabelece-se, nesses termos, que as políticas governamentais, como um tipo específico de política pública, têm por variável comum o fato de se definirem, em sua essência, pela existência de um problema público, ou, nas palavras de Secchi (2013, p. 7), "a diferença entre uma situação atual e uma situação ideal possível para a realidade pública", cujas propostas de diretrizes e intervenções para sua consecução e resolução serão emanadas de órgãos governamentais. Com isso, as políticas governamentais, da mesma forma que toda política pública, estabelecem diretrizes, formas e meios de resolução ou tratamento de situações que são coletiva e publicamente consideradas relevantes. Entretanto, por outro lado, particularizam-se como tipo específico em protagonismo, dados os seus atores principais, responsáveis pela concepção, formulação, implementação e controle, serem órgãos governamentais.

Ressalta-se, todavia, que esta definição não significa assumir que os governos não sofram influências de outros atores no processo, sendo-os tratados como esferas totalmente insuladas. Pelo contrário, a delimitação das políticas públicas de protagonismo majoritariamente estatal, tais como as políticas governamentais, pressupõe uma abordagem multicêntrica (SECCHI, 2013), pela qual se considera seu estabelecimento como resultado de intensas interações em redes de políticas públicas (policy networks), das quais participam organizações não governamentais, sociedade civil, organismos multilaterais e, especialmente, empresas - cujas ações, em particular, a partir de estratégias não mercadológicas (no-market strategy), descortinam várias práticas relevantes, a exemplo das atividades políticas corporativas (corporate political activity). Nas quais se destacam as de lobbying, doações a campanhas, mobilização de opinião pública (constituency building), coalizões, apoio às 
causas públicas (advocay advertizing), entre outras, como bem apontado por Hillman e Hitt (1999), Schuler, Rehbein e Cramer (2002) e Hillman, Keim e Schuler (2004).

Sugere-se, desse modo, que as políticas governamentais sejam tratadas como um subgrupo das políticas públicas, que, tendo por formuladores (policymakers) os órgãos dos três poderes (Executivo, Legislativo e Judiciário) e seus vinculados, possuem o objetivo de estabelecer diretrizes e meios de resolução de problemas públicos, delimitados e restritos a certos destinatários (policytakers). Em que se sobreleva o fato de tais objetivos se dão a partir da interação com outros atores, destacadamente as empresas. Por esta ótica, seu processo de elaboração pressupõe a realização de um ciclo (policy cicle), cujas etapas, como analisado por Nagel (2002), Secchi (2013), Souza (2006) e Howlett, Ramesh e Perl (2013), podem ser sinteticamente entendidas por meio da: i) identificação do problema público e de sua relevância; ii) definição e formação de agenda (agenda setting); iii) identificação e formulação de alternativas; iv) tomada de decisões; v) implementação; e, por fim, vi) avaliação e controle, conforme ilustrado na Figura 2.

Figura 2

Ciclo de políticas públicas

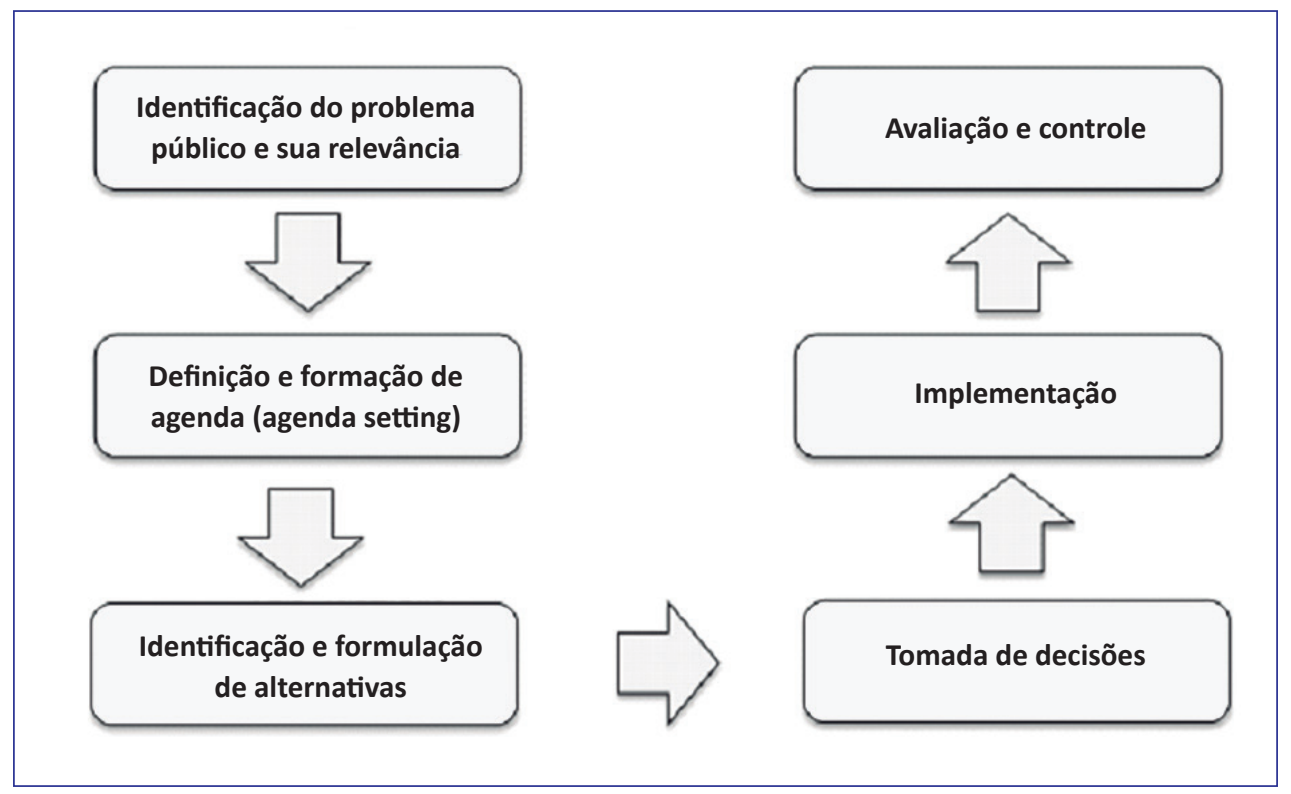

Fonte: Elaborado a partir de Nagel (2002), Secchi (2013), Souza (2006) e Howlett, Ramesh e Perl (2013).

De acordo com esse ciclo, na primeira etapa, de identificação do problema, suscitam-se e delimitam-se as questões e seus elementos que serão objetos de análise, levando em consideração sua relevância pública. Posteriormente, na formação de agenda, o processo decisório ocorrerá em torno dos elementos definidos no problema público que serão passíveis de intervenção e empenhos governamentais, resultando em diretrizes. Já na terceira etapa, de identificação e formulação de alternativas, ocorre o desenho e estabelecimento de mecanismos e instrumentos que serão utilizados, para, na etapa a seguir, serem selecionados e passarem a compor o escopo e instrumentos da política em voga. E, finalmente, nas etapas finais, decide-se o cronograma e sua forma de implementação, para, em último passo, realizar a avaliação de impactos e o controle de consecução dos objetivos estipulados.

A partir desse entendimento, incorporar a internacionalização de empresas à agenda pública e política de um país se revela nos Estados em que este processo ocorre o desenvolvimento de um ciclo de política pública (policy cicle) cujos esforços são direcionados para promoção de uma nova orientação de forma, escopo e atuação dos governos nas estratégias nacionais de desenvolvimento (IEDI, 2013). Fenômeno que acontece em evidente consequência das reconfigurações nas relações entre governos e empresas no bojo da realidade econômica global, que assumem perfis mais construtivos, cooperativos e transigentes (STOPFORD, STRANGE e HENLEY, 1991; BODDEWYN, 1992; DUNNING, 1998; GROSSE, 2005), além de possuírem 
grande complexidade e estarem refletidos nos ciclos de políticas públicas. O que ocorre, de um lado, por ações das empresas que elaboram estratégias não mercadológicas, pelas quais demandam e barganham com os órgãos governamentais, porque interessadas como destinatárias (policytakers) (HILLMAN e HIIT, 1999; SCHULER, REHBEIN e CRAMER, 2002; HILLMAN, KEIM e SCHULER, 2004). E, por outro lado, pelas as ações dos governos, que no papel de formuladores (policymakers) são compelidos a rever e propor novos tipos de instrumentos de incentivos e apoio, tendo em vista os potenciais impactos da expansão deste processo às economias nacionais.

A questão é pertinente, pois, ainda que a participação governamental no âmbito dos negócios internacionais não seja uma novidade, quando existente, ocorreu apenas nos ganhos provenientes do comércio internacional, em particular por meio de políticas governamentais de promoção das exportações, normalmente pautadas pelas dinâmicas e padrões derivados das vantagens comparativas ricardianas. Até meados do século $\mathrm{XX}$, os governos estavam restritos ao desenho de políticas comerciais e industriais de ação quer horizontal quer setorial. As intervenções governamentais que ocorriam por meio dessas políticas tinham o objetivo de incentivar os padrões comerciais considerados como os mais interessantes ao bem-estar de suas populações, o que era dado a partir da dotação de fatores e estrutura de produção e produtividade de suas economias.

Desde Adam Smith, com a publicação de A Riqueza das Nações, em 1776, o nível de análise para pensar os ganhos econômicos do comércio internacional residia nas diferenças das estruturas produtivas dos países, cujas explanações teóricas eram referentes às nações e nos porquês das vantagens do comércio exterior. Isso era realizado sem levar em consideração as estruturas e estratégias das empresas, mas apenas a disponibilidade dos fatores de uma economia, e, destacadamente, sua produtividade. Com isso, as tradicionais políticas para competitividade das empresas nacionais eram as industriais de viés protecionista e, quando do estímulo à inserção em contextos internacionais, os seus instrumentos eram direcionados pelas políticas comerciais de incentivos e subsídios à exportação; o que, por vezes, suscitou um modelo considerado neomercantilista.

Ocorre que nesse tipo de política comercial, a inserção internacional privilegiada, a exportação, é normalmente baseada em mercado interno, dado que as empresas mantêm as suas atividades de valor e produção no país. Trata-se de um perfil de política pública governamental que, embora inclua uma orientação internacional, concentra seu apoio em negócios na origem, sendo comum seu fácil apelo público e certa facilidade de mensuração de seus ganhos econômicos nacionais. No entanto, essas políticas, antes meramente comerciais, ao assumir o caráter de políticas de internacionalização, passam a abarcar todas as modalidades operacionais de negócios internacionais, desde as comerciais até o investimento direto estrangeiro, inclusive em ambas as direções: de dentro para fora (outward) e de fora para dentro (inward). Portanto, seu paradigma de formulação, escopo, intervenção e instrumentos não são triviais historicamente; novas demandas surgem.

Afinal, o processo de internacionalização extrapola as questões comerciais, da mesma forma que adentra pelas dimensões internas das empresas, em que igualmente se avulta o fato de que as características produtivas e a dotação de fatores nacionais passam a incluir novas variáveis e complexidades na realidade contemporânea. Dessa forma, há um conjunto novo de fatores que não obstante proporcione maior complexidade aos negócios internacionais, também possui o agravante de que os seus ganhos não são imediatamente perceptíveis à opinião pública na maior parte de suas estratégias, tendo em vista horizontes maiores de tempo de realização e de resultados relativamente mais difusos para economia nacional (ALÉM e CAVALCANTI, 2005; ALÉM e MADEIRA, 2010). Sendo assim, a tomada da internacionalização como problema público desencadeou o início de ciclos de políticas públicas que prenunciaram uma nova fronteira de ações governamentais específicas, uma vez que, dada a complexidade do fenômeno, as suas etapas de concepção, diretrizes, mecanismos e instrumentos de atuação acabam por demandar novas dimensões de intervenções, assim como novas propostas e estratégias, quer isoladas quer articuladas, que inauguraram novos marcos institucionais. Não por acaso, as etapas de identificação de problemas públicos, formação de agenda (agenda setting) e formulação de alternativas ao longo do ciclo das políticas governamentais de apoio à internacionalização têm ocorrido com maior diálogo e interação entre governos e empresas, sendo majoritariamente orientadas e norteadas pelas demandas empresariais.

Por conseguinte, as políticas governamentais de apoio à internacionalização, nos países em que têm sido uma opção, não estão sendo desenhadas única e exclusivamente a partir do padrão determinístico de vantagens comparativas com base em produtividade e em dotações relativas de fatores. Atualmente, também passam a incorporar aspectos das determinantes microeconômicas e estratégicas das empresas, desde as suas motivações e características até às suas vantagens de propriedade e outros fatores de ordem comportamental. Ao que tudo indica, tais políticas estão sendo formuladas e implantadas 
por meio de mecanismos e instrumentos que sejam estrategicamente alinhados com os fatores determinantes do comportamento estratégico de internacionalização das empresas geoeconomicamente contextualizadas, além de articulados com outras políticas complementares (UNCTAD, 2006). Esse processo torna sua formulação mais complexa e com demandas inventivas e inovativas, uma vez que a internacionalização de uma empresa é estrategicamente diversa, apresentando imensas variações quanto ao tipo de indústria, empresa, motivações, entre outros (MALHOTRA e HINNINGS, 2010). É o caso das características dos países de origem e de destino - fatores que dificultam a tomada horizontal e descontextualizada de ações pelos governos ou ainda réplicas de modelos exógenos. Como afirmou Porter (1989), as intervenções governamentais na realidade global ocorrem por processos extremamente localizados, internos aos países e a partir da estrutura e características de suas indústrias domésticas.

Diante dessas características, os ciclos das políticas governamentais de apoio à internacionalização tendem a ser extremamente contextualizados com relação aos seus interesses, diretrizes, indústrias e empresas apoiadas, inclusive no que concerne às características nacionais e dos países de destino e/ou de origem, não havendo a possibilidade, como notado pela UNCTAD (2006), de uma política que seja considerada "one-size-fits-all". Consequentemente, dois desafios estão presentes nesse tema: um de ordem empírica, relacionado ao seu ciclo de política pública; e outro de ordem analítica, voltado às maneiras de analisar e, principalmente, comparar, esse perfil específico de política governamental entre os países. Com relação ao fato de as políticas governamentais de apoio à internacionalização serem concebidas, formuladas e implementadas em contexto, verifica-se que os governos são compelidos a elaborar as suas abordagens e instrumentos necessariamente a partir das condições específicas prevalecentes em seus países e que reflitam seu estágio de desenvolvimento, "vantagens comparativas, posição geopolítica, estrutura e competências setoriais empresariais, e, obviamente, a estratégia nacional de desenvolvimento de seu governo." (UNCTAD, 2006, p. 201). Dessa forma, dada sua significativa variação entre os países, a análise das políticas governamentais de apoio à internacionalização normalmente tem sido tratada na literatura por meio de algumas dimensões típicas, que, ao demarcar seu escopo de atuação, não somente permitem caracterizá-las como uma política específica, mas analisá-la em meio e a partir de suas especificidades e instrumentos propostos.

Esforços analíticos nesse sentido podem ser resgatados de trabalhos que, desde o último quartel do século XX, já se alinhavam com a ideia de se tipificar políticas governamentais voltadas aos negócios internacionais, tendo por seu interesse inicial investigar as políticas comerciais direcionadas à promoção das exportações que se propuseram a ser constituídas a partir de dimensões estratégicas de suas empresas nacionais. Pesquisas como as de Seringhaus (1986), Seringhaus e Botschen (1991), Kotabe e Czinkota (1992), Diamantopoulos, Schlegelmich e Katy Tse (1993), Gillespie e Riddle (2004), Czinkota (1994) e Cavusgil e Yeoh (1994), bem como outras identificadas por importante levantamento bibliográfico realizado por Schmidt e Silva (2012), foram pioneiras e abriram uma nova frente de investigação, empenhada em analisar os impactos dos governos na promoção/incentivo às exportações nacionais, levando-se em consideração como os atores governamentais desenhavam e direcionavam instrumentos e mecanismos para atender as empresas nacionais em processo de expansão internacional comercial; prática que se tornava notória e mais intensa dos anos 1980 adiante, conforme verificado por Kotabe e Czinkota (1992).

Marco importante que sintetiza e ilustra esse processo ocorreu em 1988, quando do International Symposium on Trade Promotion and Assistance, realizado na Michigan State University, nos Estados Unidos. Naquela oportunidade ocorreram pela primeira vez discussões abertas sobre quais os papéis que os governos poderiam assumir na promoção das exportações, cujos resultados culminaram em livro organizado por Cavusgil e Czinkota (1990a). Interessante registrar que esse encontro não fora somente um debate acadêmico, mas a promoção de um diálogo no convívio de agentes governamentais, associações e atores privados, em que se buscou estabelecer uma parceria público-privado e sinergias entre as partes quanto aos recursos e talentos necessários para avançar nos processos de promoção comercial, como, posteriormente, revelaram os seus organizadores, Cavusgil e Czinkota (1990b). Objetivos que, nesses termos, permitem perceber que a ideia de interação entre as partes interessadas no processo de políticas governamentais de apoio a negócios internacionais, destacadamente governos e empresas, já se configurava dinâmica que permeava e vem acompanhando esse tipo de política específica desde seu alvorecer até seu devir contemporâneo.

Verifica-se, então, destes trabalhos citados, assim como de outros arrolados no mesmo período, o desenvolvimento, aos poucos e de maneira cumulativa, de um framework de análise das políticas governamentais especificamente direcionadas para incrementar o desempenho exportador das empresas nacionais. No entendimento de Seringhaus (1986), tais políticas compreendiam todas as medidas públicas - no caso, governamentais - que real ou potencialmente buscavam aumentar a 
atividade exportadora, tanto da perspectiva das empresas quanto das indústrias ou país. Os primeiros passos orientados para esse objetivo foram dados tanto por trabalhos empenhados em desenvolver metodologias para mensurar os impactos das ações governamentais nas exportações, como se destacam os de Seringhaus (1986) e Diamantopoulos, Schlegelmich e Katy Tse (1993), por exemplo, quanto por outros mais propositivos e normativos, como o de Czinkota (1994), ou ainda por aqueles que atuaram nessas duas frentes, bem representado pelo de Kotabe e Czinkota (1992). Sendo que todos, para consecução de seus fins de investigação, começaram a suscitar dimensões nas quais usualmente os instrumentos e mecanismos de apoios governamentais, ainda que diversos, poderiam ser tipificados por meio de uma perspectiva transnacional (cross-national). Pois, uma vez que, como constatado, os conteúdos dessas políticas fossem extremamente contextualizados, frutos de um ciclo de política pública nacionalmente constituído, seu escopo de ação era possível de ser observado por meio de uma estrutura comum de organização.

Na esteira dessa reflexão, contribuição importante fora dada por Kotabe e Czinkota (1992), que apuraram que as atividades de promoção das exportações realizadas pelos governos geralmente compreendiam: i) programas de serviços de exportação, tais como seminários para potenciais exportadores, consultoria, manuais de exportação e financiamentos de exportações e ii) programas de desenvolvimento de mercados, nos quais eram incluídos a participação em feiras, elaboração de pesquisas mercadológicas e disseminação de oportunidades de mercados. O que permitia a interpretação de que, dentro dessas dimensões, os esforços dos programas governamentais de apoio à exportação podiam ser diferenciados ante as suas intenções. Ou seja, prover (i) conhecimento experiencial ou (ii) informacional às empresas, principalmente acerca de como se exportar e sobre potenciais mercados de destinos (SINGER, 1990 apud KOTABE e CZINKOTA, 1992). Não por acaso, alguns trabaIhos, como o de Gillespie e Riddle (2004), começaram a analisar as políticas governamentais de promoção das exportações pela ótica, relevância e impacto das organizações de promoção das exportações (export promotion organizations ou trade promotion organizations), as quais, nesse contexto e dimensões, acabaram por tomar para si o protagonismo da realização e condução deste tipo de política. Para os autores, tais organizações, pelas suas características existenciais de atuar diretamente no provimento de conhecimento informacional e experiencial, acabavam por se destacar como os principais agentes de políticas governamentais de promoção das exportações em detrimento de outros programas, tornando-se, nesse sentido, fundamental a análise de suas estratégias de atuação.

Pode-se afirmar, ainda, que grande parte dessa centralidade das organizações de promoção das exportações ocorreu pela percepção dos governos de que as peculiaridades dos mercados de destino, particularmente os fluxos assimétricos de informações das mais diversas ordens, bem como os riscos institucionais existentes, eram entraves consideráveis à expansão comercial internacional das empresas nacionais, dados os elevados custos de transação envolvidos. Sendo pertinente a opção por estabelecer, no âmbito de suas políticas de promoção às exportações, esse tipo de organização como estratégia para vários países. Dessa forma, a implantação dessas organizações, normalmente no formato de agências, adquiriu grande relevância no escopo dos programas governamentais de apoio à exportação, alçando-as ao status de seus stakeholders fundamentais nas ações de indução da inserção comercial internacional de empresas nacionais. Mesmo que manifestada por meio de modelos organizacionais, hierárquicos e operacionais diferentes entre os países, a opção por esse tipo de organização foi notória (LEDERMAN, OLARREGA e PAYTON, 2006). Assim como as suas atividades, ações e programas basicamente agrupados em quatro dimensões, como verificado por Jaramillo (1992): i) identificação e desenvolvimento de produtos e mercado, ii) serviços de informação sobre comércio, iii) assistência especializada e iv) atividades promocionais no exterior.

De maneira geral, a atuação era preponderantemente interna, no país de origem, com a agência focada, sobretudo, na sensibilização, capacitação e indução das empresas domésticas para atividade de exportação. Eram poucas as ações mais incisivas nos mercados estrangeiros e, quando realizadas, normalmente vinculadas à promoção comercial, como feiras e missões. $A$ principal atividade dessas agências em seu início era a de identificar produtos e mercados, o que era realizado por meio de pesquisas mercadológicas (JARAMILLO, 1992). Em outras palavras, os seus objetivos basilares eram o de "ajudar as empresas nacionais a achar mercados para os seus produtos, assim como prover um melhor entendimento dos produtos demandados por diferentes mercados" (LEDERMAN, OLARREGA e PAYTON, 2006, p. 1-2).

A análise desse contexto emergente a partir dos anos 1980, levada a cabo pelas reflexões ora referenciadas, de certa maneira motivou o compartilhamento de uma ideia comum dentre diversos acadêmicos, governantes e empresários à época, de que, como expressou Lewis (1990), os governos podem, e devem, ter papel importante no estímulo aos negócios internacionais, principalmente no caso de pequenas empresas e daquelas neófitas na exportação. O que deve ocorrer por meio de políticas 
de promoção às exportações que incluam programas de assistência e suporte que, a despeito de várias formas, normalmente abarquem: i) a criação de clima favorável e de incentivos à exportação, ii) ajuda para superar barreiras de entrada em mercados estrangeiros, iii) crédito e financiamento às exportações, iv) informações atualizadas sobre oportunidades de mercado, contatos e canais de relacionamento e a v) promoção de oportunidades no exterior por meio de exibições e rodadas prospectivas de clientes (LEWIS, 1990).

Com isso, o entendimento dado no final do século XX a esse tema era de que os governos começaram a se mobilizar para incentivar as exportações nacionais, direcionando esforços e recursos em ações que buscassem atender às necessidades e fragilidades de suas empresas domésticas, em particular as de pequeno porte, por meio do oferecimento de suporte informacional e conhecimento experiencial. O que era majoritária, mas não exclusivamente - tendo em vista instrumentos de outras ordens não menos importantes, como os financiamentos e os incentivos fiscais - conduzido por meio de organizações especificamente constituídas no formato de agências para promover esses fins; no caso, as trade promotion organizations.

Esse alinhamento analítico entre autores acerca do papel dos governos e de seu escopo e forma de atuação na promoção das exportações pode ser corroborado internacionalmente por meio das decisões governamentais que foram tomadas mundo afora ao longo do período. Como averiguado por Lederman, Olarrega e Payton (2006), essas decisões fizeram o número de organizações de promoção das exportações triplicar nos últimos trinta anos, bem como foi apurado que diversos países passaram a empenhar mais recursos em ações de incentivos à inserção comercial internacional de empresas nacionais (SINGER, 1990 apud KOTABE e CZINKOTA, 1992). Os estudos acadêmicos, teóricos ou empíricos, seguiram essa orientação em outras regiões, reconhecendo esse papel crescente dos governos na promoção das exportações como problema de pesquisa pertinente e relevante, incrementando sua produção internacionalmente. No Brasil não fora diferente. Ainda que com estudos mais escassos do que a média internacional, nota-se no país, desde a virada do século XX, crescente número de trabalhos que foi orientado para refletir as políticas governamentais brasileiras de promoção das exportações. Seja por meio de ótica propositiva ou descritiva de suas diretrizes, formato, ações e instituições, como Abreu (2002), Veiga e Iglesias (2002) e Markwald e Puga (2002), ou ainda empírica, focada em sua efetividade, tais como Grimaldi e Carneiro (2010), Albuquerque (2008) e Alvarez (2013), inclusive com aqueles dedicados exclusivamente ao protagonismo da export and investment promotion organization (EIPO) nacional, a Apex-Brasil, como encontrado em Pianto e Chang (2007) e Coluchi (2011).

Neste contexto, um ponto pertinente merece destaque e reflexão: o protagonismo observado das agências de promoção nas políticas governamentais de apoio às exportações. A justificativa de suscitá-lo encontra-se no fato de que descortina questões relevantes sobre as modificações recentemente observadas de escopo e de atuação dos governos no incentivo aos negócios internacionais, cujas motivações têm sido decorrentes, em grande parte, da complexidade que o fenômeno da internacionalização adquire com a consolidação de uma economia global. Ao analisar a evolução histórica das estratégias das agências de promoção das exportações, é possível constatar que, não obstante os esforços e ações para expansão comercial internacional de empresas nacionais, tais empreendimentos têm ampliado seu escopo de atuação, empenhando-se em outras frentes, principalmente naquelas que incluem formas mais avançadas de inserção internacional, porque promotoras de maiores riscos e comprometimento de recursos no exterior. Tal fato tem ocorrido não somente no apoio aos investimentos diretos estrangeiros e ao estabelecimento de relações contratuais a partir da origem, mas, da mesma forma, em atividades e serviços de suporte mais complexos e baseados nos mercados estrangeiros. O que se verifica é que as agências de promoção contemporâneas, a despeito de continuarem a formar robusta base no país de identificação de empresas/produtos potenciais e a capacitar e induzir empresas aos negócios internacionais, também iniciaram novo portfólio de suporte e apoio, começando a se estabelecer nos mercados de destino, assim como passaram a se engajar na defesa de interesses empresariais nacionais a partir do e no estrangeiro.

Importantes agências de promoção no mundo migraram de modelo, estrutura e complexidade nessa direção, em que se destacam a britânica UKT\&I, a sul-coreana Kotra e a espanhola Icex, por exemplo, incluída a brasileira Apex-Brasil. As quais, ademais, propiciaram mudanças de classificação, tornando-se, agora, export and investment promotion organization, em junção das funções de trade promotion organization e investment promotion agency (COELHO e ROCHA, 2013). São agências que não apenas se instalam e marcam presença nos mercados estrangeiros potenciais, como se vinculam fortemente a eles, adquirindo status de grandes facilitadoras de inserção, constituindo redes capazes de mobilizar agentes privados e públicos de várias esferas e competências. Chegam, inclusive, a assumir o papel de incubadoras de empresas naqueles mercados, oferecendo espaço físico e consultoria para instalação local. Tornam-se, nesse entendimento, grandes players catalisadores 
e promotores de soft landing. Isto é, agentes de facilitação de acesso e instalação nos mercados de destino, não apenas com apoio e suporte direto, tais como consultoria e infraestrutura, mas conjuntamente com a mobilização de outros atores capazes de auxiliar empresas em suas estratégias de inserção.

Nota-se, no esteio dessas transformações, que a modificação do papel das agências de promoção representa evidência de um processo maior, que vem ocorrendo, aos poucos e gradativamente, em todo escopo, diretrizes e instrumentos das políticas governamentais de apoio às exportações de vários países, cujos modelos passam a abarcar o suporte para os negócios internacionais como um todo. Verifica-se a preferência contemporânea por incentivar não exclusivamente a modalidade das exportações, mas todas as formas e modos de internacionalização. A percepção desse processo, de certa forma evolutivo nas políticas governamentais voltadas aos negócios internacionais, é notória. Despertou, igualmente, o interesse de diversos organismos internacionais, com destaque para UNCTAD (2006), ou ainda outros nacionais, como no caso brasileiro do Ipea (2012), em iniciar a análise, independentemente de suas origens, do comportamento dos governos com relação à agenda de negócios internacionais das empresas em suas respectivas economias nacionais. Tais organismos se empenharam, sobretudo, em diferenciar em suas abordagens analíticas aquelas políticas governamentais especificamente direcionadas aos negócios internacionais, no caso, à internacionalização de empresas, de outras que, indiretamente, também podem influenciar esse processo, por exemplo, as cambiais, educacionais, de ciência e tecnologia, industriais, dentre outras. Pode-se afirmar que, da mesma forma que a literatura dos anos 1980 empenhou os seus esforços para tentar tipificar transnacionalmente as políticas de promoção das exportações em estrutura comum de análise, órgãos como a UNCTAD e Ipea também se propuseram a mesma tarefa recentemente. Porém, acerca de uma política governamental agora preocupada e voltada a apoiar a internacionalização de maneira mais abrangente e inclusiva quanto às suas modalidades e direções.

Nesse contexto, padrão mais bem acabado de classificação deste tipo de política governamental foi desenvolvido pelo Ipea (2012), cujas referências primárias foram as dimensões e instrumentos definidos em relatório publicado pela UNCTAD (2006). Os quais, ademais, retomam considerável e claramente as dimensões e estrutura comum de organização anteriormente utilizadas para as políticas exclusivamente destinadas à promoção das exportações. De acordo com o Ipea (2012), as políticas governamentais específicas de apoio à internacionalização podem ser tipicamente apreendidas a partir de seis dimensões: i) apoio informacional, assistência técnica e outras orientações, ii) criação de comfort zone, iii) instrumentos fiscais e tributários, iv) instrumentos de mitigação de risco, v) instrumentos de financiamentos e vi) acordos internacionais.

Nesta classificação, a primeira dimensão abarca todos os mecanismos e instrumentos governamentais direcionados a propiciar suporte informacional e por vezes experiencial às empresas em processo de internacionalização, cujos objetivos primários estão direcionados às reduções de assimetrias de informação e de custos de transação. Na segunda, entendida como "criação de comfort zone", posicionam-se as ações voltadas a criar, nos países de destinos, instituições do tipo "one stop point", onde seja possível prover e desenvolver serviços e redes de contato capazes de propiciar à empresa demandante uma chegada facilitada e apoiada ao seu destino, o que normalmente é denominado na literatura como soft landing. Por sua vez, os "instrumentos fiscais e tributários" são caracterizados por todos os incentivos fiscais e tributários promovidos pelos órgãos governamentais, sejam de isenções, suspensões, reduções ou restituições. Já a quarta dimensão, de "instrumentos de mitigação de risco", incluem-se todas as garantias de cobertura e seguro direcionadas a reduzir riscos associados a restrições de transferência de moedas, expropriações, guerras e demais situações de instabilidade econômicas e políticas. Na dimensão "instrumentos de financiamentos", encontram-se os incentivos creditícios disponibilizados pelos governos às empresas nacionais, destacadamente as linhas de financiamentos específicas à internacionalização, empréstimos preferenciais, equity e créditos. E, por fim, em sua última frente, situam-se os "acordos internacionais", os quais incluem todas as negociações internacionais que constituíram arranjos institucionais para proteção jurídica de investimentos e eliminação de bitributação, em especial.

Verifica-se, dessa maneira, uma classificação que organiza em torno de variáveis críticas do processo estratégico de expansão de qualquer empresa contemporânea, a saber: informação, suporte/apoio, carga tributária, riscos, financiamentos e segurança jurídica, com o mérito de contextualizá-las no envolvimento com mercados estrangeiros; o que, ressalta-se, especifica tais instrumentos e mecanismos como de uma política direcionada. Entretanto, embora os esforços pertinentes e válidos da classificação elaborada pelo Ipea (2012), ou ainda sua raiz, primeiramente realizada pela UNCTAD (2006), torna-se importante ressaltar que o entendimento dado por esses órgãos, assim como por outros autores que vêm tratando do tema, como Além e Cavalcanti (2005), Sennes e Mendes (2007), Wang, Hong, Kafouros et al. (2012) e Bazuchi, Zacharias, Broering et al. (2013), é o de que tais políticas se concentram no apoio à internacionalização realizada apenas em sua expansão internacional via 
investimento direto estrangeiro, principalmente o de saída (outward). Em outros termos, constata-se que essa classificação tem sido utilizada para analisar as políticas governamentais de apoio ao investimento direto de empresas nacionais no estrangeiro. A qual adquire, no limite, a forma de referencial destinado a investigar quais são as políticas nacionais dos governos para promover a formação de multinacionais de suas economias. Logo, não são incluídas ou destacadas outras possibilidades operacionais de negócios internacionais, tais como as comerciais e/ou as contratuais, tampouco em sua direção de fora para dentro (inward).

Porém, é importante registrar que tal propensão a pensar essa classificação para apoio à internacionalização via investimento direto estrangeiro em detrimento de outras formas e modalidades de inserção internacional advém, historicamente, da polifonia teórica acerca do conceito de internacionalização. Não é incomum encontrar na literatura acadêmica e debates empresariais a distinção entre exportação e internacionalização. Na maioria dos casos, há a presença de forte viés de interpretação para a internacionalização como uma expansão internacional por meio de investimento, enquanto a exportação apenas uma operação de vendas ao estrangeiro - entendimento em grande parte dado pelo fato de que, nas exportações, as empresas praticamente estão baseadas em sua origem. Todavia, defende-se neste ensaio que a internacionalização trata de fenômeno abrangente, que incorpora todas as modalidades e formas, inclusive em suas duas direções, seja de dentro para fora (outward) ou de fora para dentro (inward). Interessante notar que, não obstante ainda exista o predomínio dessas interpretações segregativas entre exportações e investimentos, e não as inclusivas, já é possível observar inclinação de alguns setores, empresariais, inclusive, ao entendimento que caminha ao encontro deste entendimento defendido.

Caso evidente ocorreu com a agência brasileira de promoção, a Apex-Brasil, cuja evolução institucional de sua missão ao longo dos anos demonstra passos orientados à inclusão de todas as modalidades e formas de envolvimento internacional no conceito de internacionalização. Até o início do século XXI, a missão da Apex-Brasil era totalmente voltada à promoção das exportações brasileiras; sua razão existencial era dada por ações que promovessem as exportações brasileiras, tanto motivada pela expansão da base exportadora nacional, quanto pela busca da diversificação de sua pauta. Posteriormente, no adentrar dos anos 2000, passou a "promover as exportações de produtos e serviços brasileiros, contribuir para internacionalização das empresas brasileiras e atrair investimentos para o Brasil". Ou seja, não apenas ampliou seu escopo para serviços, como também incluiu investimentos, o que pode ser denotado da ideia de internacionalização, da mesma forma que incorporou direção, ao optar por atrair os aportes de capital de longo prazo de empresas estrangeiras para o Brasil. Essa missão perdurou até o final de 2011, quando, após novo planejamento estratégico, a agência decidiu-se por não somente continuar a apoiar as exportações e os investimentos brasileiros, mas deixou de tratá-los como estratégias distintas com relação à natureza do fenômeno. Dessa maneira, assumiu que seu mais novo papel institucional é o de "desenvolver a competitividade das empresas brasileiras, promovendo a internacionalização dos seus negócios e a atração de Investimentos Estrangeiros Diretos (IED)" (APEXBRASIL, 2013). Assim, verifica-se que, atualmente, o entendimento institucional dado pela Apex-Brasil acerca do fenômeno da internacionalização não segrega as suas modalidades e formas de envolvimento operacional: trata tanto as exportações quanto os investimentos, embora de complexidades diferentes, como facetas de um mesmo processo, o de internacionalização. Nesses termos, sua nova missão vincula a internacionalização como estratégia atrelada, porque seu motor, à competitividade das empresas nacionais, apenas destacando que, acerca da direção passível de apoio, especificamente naquelas situações de fluxos de fora para dentro (inward), a agência somente atuará em operações de investimentos diretos estrangeiros.

O assunto é relevante de nota, pois, nesses termos de análise, somada a defesa de que a internacionalização é conceito inclusivo, não segregativo, torna-se possível que a tipologia desenvolvida pelo Ipea (2012) a partir da UNCTAD (2006) não seja exclusivamente utilizada para casos de políticas governamentais de apoio ao investimento direto no estrangeiro, mas também às exportações e outras modalidades, como relações contratuais e importações. Pode-se considerá-la uma classificação útil para todas as medidas dos governos no suporte e incentivo à internacionalização; ou seja, aos negócios internacionais de empresas nacionais. Esta possibilidade ocorre, uma vez que, como argumentado neste ensaio, as dimensões utilizadas na tipologia não são pertinentes apenas às dinâmicas estratégicas dos investimentos diretos, mas também a outros modos e operações de envolvimento internacional. Afinal, ainda que muito se altere em conteúdo estratégico, complexidade, custos e riscos entre as formas e modos de internacionalização, todos possuem em comum o fato de serem decisões e processos de envolvimento com e por vezes no exterior, os quais são caracterizados por dimensões comuns passíveis de intervenções e mecanismos pelos governos. Visto que são pertinentes a todas as modalidades; a saber, questões como: assimetria de informação; custos de transação; suporte financeiro; proteção ao risco; facilitação; entre outros. Logo, sugere-se e defende-se no 
presente ensaio uma tipologia de classificação de políticas governamentais que seja utilizada para analisar o suporte e incentivos dos governos à internacionalização das empresas de suas economias nacionais, sendo as suas componentes estruturalmente tratada em torno de eixos comuns, conforme ilustrado na Figura 3.

Figura 3

Dimensões tipológicas das políticas governamentais de apoio à internacionalização de empresas

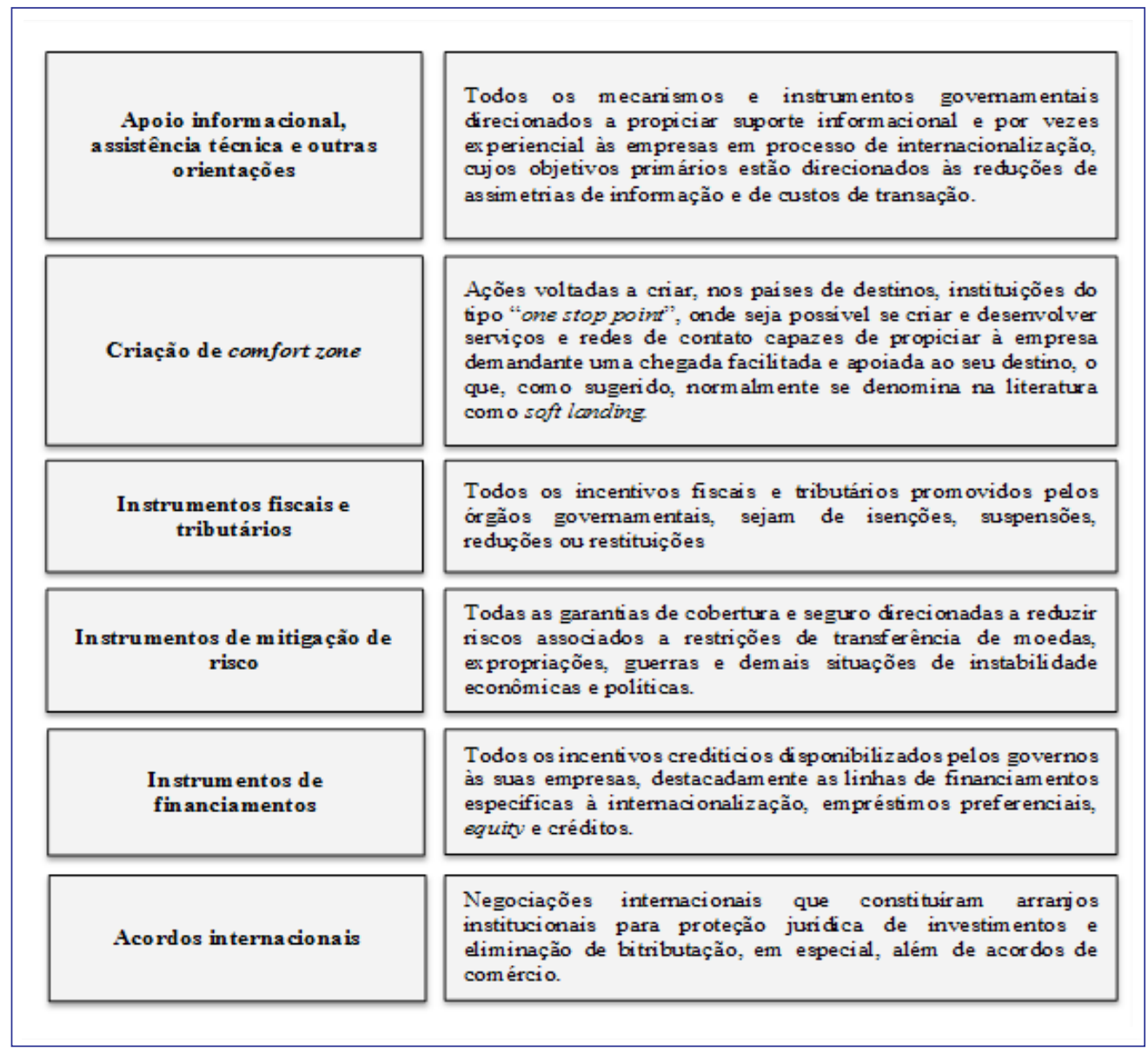

Fonte: Elaborada pelo autor a partir de UNCTAD (2006), Acioly Lima e Ribeiro (2011) e IPEA (2012).

\section{A INTERNACIONALIZAÇÃO DE EMPRESAS COMO PROBLEMA PÚBLICO DAS POLÍTICAS GOVERNAMENTAIS: IMPACTOS E IMPLICAÇÕES TEÓRICAS E EMPÍRICAS}

A argumentação engendrada até o momento neste ensaio demonstrou que o debate acerca do papel dos governos no processo de internacionalização de empresas vem ganhado destaque na literatura (UNCTAD, 2006; BUCKLEY, 1998; WANG, HONG, KAFOUROS et al., 2013; GUEDES, 2006), particularmente os seus efeitos em potencializar ou inibir este processo (LEMOS, 2013). Nesse contexto, questão proeminente é direcionada à participação dos governos na internacionalização de empresas nacionais, por meio de seu incentivo, apoio e suporte via políticas públicas específicas e direcionadas para estes fins (UNCTAD, 2006; ALÉM e CAVALCANTI, 2005; IPEA, 2012). Importante destacar que o direcionamento do olhar a tais questões não decorre simplesmente das modificações nas dinâmicas da competição internacional, mas também em grande parte motivado pelas decisões estratégicas tomadas e deliberadas pelos governos de importantes países emergentes, como Índia e China, cujo grupo majoritário tem demonstrado adotar políticas públicas específicas como ações para incrementar a 
competitividade de suas empresas internacionalmente, apoiando os seus processos de internacionalização (UNCTAD, 2005; 2006; 2008; BARRAL, 2011; IPEA, 2012).

Como analisado, a questão é pertinente, pois a participação dos governos no âmbito dos negócios internacionais, quando existente, foi dada nos ganhos provenientes do comércio internacional, principalmente por meio de políticas comerciais de promoção das exportações pautadas pelas dinâmicas e padrões derivados das vantagens comparativas ricardianas. Contudo, o processo de internacionalização das empresas extrapola essas determinantes e somente as características produtivas e a dotação de fatores nacionais não se tornam mais suficientes para interpretação deste fenômeno. As atuais políticas governamentais de apoio à internacionalização, quando uma opção dos países, estão sendo formuladas além da exclusividade dada ao padrão determinístico das vantagens comparativas com base em produtividade e em disponibilidade relativa de fatores, incorporando dimensões ao nível das empresas, por meio de instrumentos fiscais, creditícios, financeiros e de suporte informacional, assim como em recursos e competências que Ihe são internas (UNCTAD, 2005; 2006; 2008; IPEA, 2012; WANG, HONG, KAFOUROS et al., 2012).

Evidenciou-se, assim, que a internacionalização de empresas nacionais passa a ser considerada pela agenda governamental como um problema público, sendo, em grande parte dos países emergentes, objeto de propostas e, fundamentalmente, de ações (IPEA, 2012; UNCTAD, 2005; 2006). Com isso, pode-se concluir que o fenômeno de expansão internacional das empresas não somente foi incorporado à agenda governamental de vários países, mas, nos termos de Kingdon (2003), àquela voltada a especificação de alternativas políticas (policy formulation), porque já fruto de decisões e instrumentos específicos e direcionados ao seu incentivo, suporte e indução.

Nesse contexto, o Brasil é caso proeminente. Atualmente, já se torna possível identificar no País a inclusão da internacionalização como um problema público no âmbito do ciclo de políticas públicas governamentais, o que pode ser observado desde suas etapas pré-decisórias, passando pela formação de agenda, até as suas decisões, em um modelo de múltiplos fluxos (KINGDON, 2003) de interações entre governos (policymakers) e empresas (policytakers). Elementos-chave para corroborar tais afirmações podem ser encontrados, a título ilustrativo, em sua etapa pré-decisória, com destaque ao Termo de Referência: Internacionalização de Empresas Brasileiras, de 2009. Elaborado na forma de documento analítico-conceitual, sua formulação foi direcionada para entender e mapear conceitualmente o fenômeno da internacionalização de empresas, tornando-se o "marco inaugural" do "debate para consolidar uma posição do Governo Federal [...] a fim de preparar o ambiente para interlocução qualificada com o setor privado e construir a agenda de ações em coordenação entre governo, meio empresarial e academia" (CAMEX et al., 2009, p. 9) na elaboração de propostas de políticas governamentais que facilitem o processo de inserção internacional das empresas brasileiras. Nesses termos, tratou-se de documento governamental que consolidou um trabalho teórico em amplo debate com o setor privado, em que se se buscou não apenas lançar luz sobre o fenômeno da internacionalização aos policymakers, mas, indubitavelmente, refletir sobre sua pertinência como problema público.

Não por acaso, as suas conclusões suscitaram pontos que ratificaram a internacionalização de empresas como fenômeno em pleno curso no cenário econômico atual, que, não somente ocorre de diversas formas, como também, em muitos casos, sem incentivo governamental; uma vez que as empresas não esperam - e nem têm condições de esperar - que os seus governos sejam facilitadores dessa estratégia (CAMEX et al., 2009). Foi assumido nesse Termo de Referência que governo brasileiro deve "estabelecer o equilíbrio na atuação das políticas públicas para fomentar o desenvolvimento em sua plenitude", cabendo a si, consciente da dimensão do fenômeno da internacionalização, o papel de elaborar "estratégias adequadas que permitam transformar as oportunidades em benefícios efetivos para o país", criando "condições de competitividade para que as empresas brasileiras alcancem voos mais longos e duradouros." (CAMEX et al., 2009, p. 27-28). Portanto, o documento explicita tanto o reconhecimento do processo de internacionalização das empresas brasileiras ora em curso, quanto os seus vínculos com o desenvolvimento do país. O que, consequentemente, levou ao entendimento de se tratar de um objeto de políticas governamentais, porque um problema de interesse nacional.

Inclusive, algumas decisões governamentais já foram tomadas e direcionadas ao tema, em que se destacam, recentemente, aquelas no âmbito do Plano Brasil Maior 2011/2014. Um dos pontos avultados no marco estratégico deste Plano abarca explicitamente a questão das políticas de apoio à internacionalização. Em seu texto, organizado em torno de cinco diretrizes setoriais, a Diretriz Setorial 4 expressa o que se pretende acerca da inserção internacional das empresas brasileiras, cuja dissertação assume a diversificação das exportações (mercados e produtos) e a internacionalização corporativa como objetivos 
do Governo Federal. Conforme os seus itens, o Plano buscará: i) "a promoção de produtos manufaturados de tecnologias intermediárias e de fronteiras intensivos em conhecimento"; ii) o "aprofundamento do esforço de internacionalização de empresas nacionais líderes em commodities para empresas líderes com capacidade de diferenciação de produto, agregação de valor e acesso a novas tecnologias"; e o iii) "enraizamento de empresas estrangeiras objetivando a instalação de centros de P\&D no país para a adoção das melhores práticas produtivas." (BRASIL, 2011, p. 16).

A análise desses documentos e diretrizes (Termo de Referência e Brasil Maior) permite marcar um momento importante na trajetória das políticas governamentais brasileiras de apoio aos negócios internacionais das empresas nacionais. Afinal, é possível verificar um movimento que evidencia, de forma cada vez mais explícita e deliberada, de que o apoio à inserção internacional empresarial brasileira passa a compor a agenda estratégica nacional do Brasil, tornando-se problema público, logo objeto de políticas governamentais. Pode-se concluir, igualmente, que a internacionalização de empresas, seja por meio de um marco teórico, tal como o Termo de Referência, seja por outro estratégico, como o Brasil Maior, já pode ser considerada um fenômeno das agendas de políticas governamentais e de alternativas à ação pública (policy agenda-setting e policy formulation) (KINGDON, 2003) brasileiras no contexto contemporâneo, como uma importante frente das estratégias de desenvolvimento adotadas pelo País, assim como por outros emergentes.

Entretanto, quais são as implicações teóricas e empíricas desse novo ciclo de políticas públicas, que incorpora a internacionalização de empresas como problema? Nesse toar indagativo, algumas questões podem ser suscitadas. Em âmbito teórico, destacam-se as potenciais contribuições à Administração e aos Negócios Internacionais. Particularmente, o fato de que a incorporação das políticas governamentais de apoio à internacionalização poder ser considerada um fator-chave para descortinar algumas lacunas das abordagens teóricas do envolvimento internacional das empresas, especificamente em sua utilização para caracterizar os processos daquelas oriundas de países emergentes. Pois, como parte da literatura da área recentemente revela, há intenso debate sobre a necessidade ou não de revisitar referenciais anteriores, ou ainda de elaborar novos, com o propósito de desenvolver interpretação mais bem adequada para contemporaneidade do fenômeno e de suas determinantes no alvorecer do século XXI (RAMAMURTI, 2012; HENNART, 2012). Dentre os temas mais debatidos nesse contexto, encontra-se a internacionalização de empresas dos países considerados emergentes, comumente denominada na literatura como entrantes tardios (late movers) (FLEURY e FLEURY, 2007); as quais se destacam, visto que têm incrementado consideravelmente seu nível de envolvimento internacional, promovendo, inclusive, o reordenamento dos fluxos comerciais, de investimento e financeiros mundialmente.

Nessa linha, investigações recentes têm enfatizado que o processo de internacionalização de empresas de países emergentes possui peculiaridades que fogem ao escopo das teorias tradicionais (RAMAMURTI, 2009; HENNART, 2012), cuja conclusão, para Fleury e Fleury (2007, p. 3), é a de que ainda não há, com robustez, "uma abordagem teórica que trate especificamente das chamadas 'empresas entrantes tardias'", uma vez que as existentes foram formuladas a partir de diferentes quadros de referência; fato que coloca os pesquisadores predispostos a estudar essas empresas em posição ambígua (FLEURY e FLEURY, 2007).

Na busca para descortinar as determinantes da internacionalização destas empresas, autores como Child e Rodrigues (2005) assumem que as multinacionais de países emergentes muitas vezes se internacionalizam para corrigir desvantagens competitivas e não, como esperado pelas teorias mais tradicionais do mainstream econômico, motivadas e sustentadas por vantagens que Ihe são específicas. Bhaumik, Driffeld e Pal (2010), assim como Luo e Tung (2007) e Wang, Hong, Kafouros et al. (2012), inclusive, afirmaram que, contrária às predições teóricas tradicionais, as empresas de países emergentes estão incrementando as suas operações internacionais, o que inevitavelmente suscita novas questões sobre as determinantes desse processo.

Constata-se, neste ponto, lacuna teórica na área de Negócios Internacionais, principalmente no que concerne à apreensão das diferenças entre os processos de internacionalização de empresas de países tradicionais e a dos emergentes, cujos contornos mais fortes são avultados quando tratados à luz das teorias consideradas pelo mainstream econômico, dentre as quais, sua maior expressão, o Paradigma Eclético de John Dunning, sugere que a inserção internacional ocorre a partir de vantagens específicas, destacadamente de propriedade das firmas. O que, para Wang, Hong, Kafouros et al. (2012), evoca questão fundamental: se as empresas multinacionais de países emergentes, reconhecidas internacionalmente por ainda não terem posse de capacidades destacadas (strong capabilities) diante daquelas de países tradicionais, estão incrementando consideravelmente os seus investimentos diretos no exterior, ou seja, em modo operacional de internacionalização de maior risco e comprometimento de recursos, quais seriam, então, as forças que têm atuado e direcionado o envolvimento internacional destas empresas? 
A questão é pertinente, pois, como propugnado pelos modelos mais utilizados na interpretação da internacionalização das empresas, a saber, o Paradigma Eclético de Dunning, de ótica econômica, e a Escola de Uppsala, de ótica comportamental, a expansão internacional de um empreendimento é basicamente dada por características que lhes são próprias, isto é, internas, e, quando externas, fundamentalmente determinadas por distâncias e diferenças institucionais, culturais, econômicas ou políticas, que podem, em maior ou menor grau, impactar o risco percebido do tomador de decisão ou ainda os custos de transação, direcionando a uma estratégia em detrimento de outras. Sendo, nesse ponto de reflexão, que uma dimensãochave emerge: os governos.

Afinal, como analisou Lemos (2013), embora o governo seja ator reconhecido na agenda de pesquisa de Negócios Internacionais, seu papel no processo de internacionalização tem se mostrado pouco explorado. Ademais, ainda que a literatura de Ciência Política já tenha incorporado o fenômeno da internacionalização como uma questão emergente nas relações entre governos e empresas (BODDEWYN, 1992; STOPFORD, STRANGE e HENLEY, 1991; DICKEN, 2010; STRANGE, 1994; 1996; 2000; GROSSE, 2005; VIETOR, 2007; GUEDES, 2006; MUSACCHIO e LAZZARINI, 2013; CAMILO, MARCON e BANDEIRA-DE-MELLO, 2012), como, inclusive, demonstrado neste ensaio, são poucos os estudos que se dedicaram a explorar tais interações pela ótica das dinâmicas dos negócios da indústria (LEMOS, 2013).

Conforme atestaram Sousa e Lemos (2009), uma das possíveis explicações para a baixa associação entre governos e empresas nesse tipo de estratégia internacional na literatura decorre, dentre outros fatores, do fato de que há um amplo consenso constituído em torno da racionalidade do processo de internacionalização como uma questão (issue) específica das empresas (firm-specific), como sugerido pelos seus principais modelos de interpretação, o Paradigma Eclético e a Escola de Uppsala. $O$ que não se justifica totalmente, pois, como observou Buckley (1998), as empresas não enfrentam as suas questões, particularmente a formação de vantagens específicas, no vácuo. Mas em ambientes em que outros atores são relevantes, com destaque aos governos. Sousa e Lemos (2009), por exemplo, defenderam que os governos assumem papéis, ainda que limitados, tanto ao nível macro quanto micro, os quais podem, por um lado, promover ambientes mais propícios à internacionalização, como, por outro lado, também prover instrumentos diretos determinantes das escolhas das empresas. Nesse raciocínio, Wang, Hong, Kafouros et al. (2012) foram além, argumentando que os governos, em suas atuações de fornecer informações, reduzir custos de transação e diminuir a restrições de recursos, assim como influenciar as decisões dos tomadores de decisão das empresas, como as maneiras de alocar os seus ativos (WANG, HONG, KAFOUROS et al., 2012), podem ser importantes fatores de vantagens das empresas.

Pelo exposto, argumenta-se e sugere-se no presente ensaio que as políticas governamentais podem se tratar de uma nova variável interpretativa, capaz de explicar parte do processo de internacionalização de uma empresa nacional. Dessa forma, seriam tomadas como um potencial fator de vantagens, que, via internalização de instrumentos públicos nas empresas, poderia explicar a expansão internacional ante demais concorrentes estrangeiras. Portanto, incluir teoricamente as políticas governamentais de apoio aos negócios internacionais como um possível fator de vantagens de localização da origem que pode ser internalizado pelas empresas como vantagens de propriedades facilitadoras da internacionalização, uma inferência que pode descortinar questões pertinentes sobre este fenômeno, principalmente em países emergentes. Assim, sugere-se no presente ensaio que os governos e suas políticas à internacionalização sejam assumidos como potenciais recursos para internalização das empresas na forma de vantagens de propriedade, quer transacionais quer de posse de ativos, ou ainda comportamentais, de qualificação executiva, permitindo a expansão dos referenciais teóricos dos Negócios Internacionais, tanto aqueles de abordagem econômica, com destaque ao Paradigma Eclético de Dunning e suas vantagens de localização (L), quanto da Escola de Uppsala, com relação ao conhecimento experiencial e técnico.

Ressalta-se, todavia, que tal sugestão de incorporar os governos de origem por meio de suas políticas governamentais como potenciais variáveis de vantagens da internacionalização inevitavelmente demanda a reflexão empírica deste processo, principalmente à Ciência Política. Afinal, trata-se de um problema público associado ao desenvolvimento dos países, mas que, essencialmente, ocorre por meio do suporte governamental ao setor privado. Dessa maneira, o ciclo de política pública das políticas de apoio à internacionalização pressupõe intensas interações entre governos e empresas, cujo resultado, em grande parte das vezes, pode emanar de barganhas e pressões de setores organizados, os quais consigam se beneficiar em detrimento de outros. Neste mesmo raciocínio, talvez seja possível constatar que alguns grupos de pressão empresariais, com maiores poderes estruturais de barganha, podem instrumentalizar os recursos públicos a seu favor, sob este discurso do desenvolvimento nacional - sendo os casos mais notórios as políticas governamentais de apoio à internacionalização formuladas pelas estratégia de escolha das campeãs nacionais, em que algumas empresas, consideradas como potenciais global players, recebem apoio incisivo, inclusive patrimonial, do Estado. Não ocasionalmente, tais políticas, em vários países, são 
fortemente questionadas quanto aos seus méritos e interesses. Por outro lado, também pode-se descortinar, pela ótica das políticas públicas, análise das eficácias de seus objetivos (public policy analysis), podendo ser empiricamente qualificada como variável de impacto ou não nesse processo, o que, de certa forma, pode revelar desafios e oportunidades nacionais e empresariais diante da competição internacional.

Por tais características, é importante frisar que a dimensão e a repercussão política da incorporação da internacionalização de empresas como problema público não permitem que seu processo analítico seja tomado unidimensionalmente, com foco somente em seus instrumentos como variáveis explicativas do envolvimento internacional das empresas. Mas, indubitavelmente, também em sua dinâmica de formulação, a qual inclui agendas e barganhas entre grupos governamentais e empresariais que determinarão suas diretrizes e instrumentos. Afinal, tais processos revelam, pela ótica das ações não mercadológicas empresariais, como lobbying, advocacy, financiamento de campanha e outras, um contexto de formulação e de decisão de agenda de políticas que não é linear e tampouco horizontalizado na maior parte dos casos. Pelo contrário, pressupõe diversos níveis de complexidade, interações e barganha, resultantes de diversos interesses e conflitos setoriais. Não por caso, considerado o Brasil, ainda não há, por parte do Governo Federal, um marco institucional mais explícito e deliberado das políticas governamentais de apoio à internacionalização em curso no País. Os seus instrumentos ora disponíveis estão por vezes insulados em algumas ações ministeriais, outras do BNDES e da Apex-Brasil, uma vez que o tema da internacionalização de empresas, particularmente via investimentos diretos, ainda não é consenso em todos os setores da sociedade como um problema público objeto de políticas governamentais (ALÉM e CAVALCANTI, 2005), logo, passível de diversas contrariedades e manifestações, como já ocorrido, inclusive (ILHA, 2011; DETAQ-CD, 2011). Questão proeminente deste cenário, a título ilustrativo, foi relevada pelo anúncio público do BNDES de uma política de campeãs nacionais, a qual, de tão criticada quanto aos seus méritos e critérios, foi abandonada em curto espaço de tempo (VALOR, 2009).

\section{CONSIDERAÇÕES FINAIS: PROPOSTA PARA UMA AGENDA DE PESQUISA}

A reflexão proposta neste ensaio se desenvolveu em torno da investigação da incorporação do fenômeno da internacionalização de empresas à agenda governamental, particularmente na formulação de políticas de incentivo e apoio ao envolvimento internacional de empresas nacionais. Assumiu-se, portanto, que as políticas governamentais de apoio à internacionalização e seu ciclo político de formulação promovem impactos teóricos e empíricos na área de Negócios Internacionais, os quais não podem ser relevados. Afinal, como investigado, torna-se cada vez mais evidente que as relações entre governos e empresas passam por reconfigurações no contexto da economia global, encontrando na competição internacional e na internacionalização os seus fenômenos mediadores. Tal processo pode ser observado em vários países, com maior destaque nos emergentes, cujos governos deliberadamente passam a apoiar e a induzir a internacionalização de empresas nacionais. Nota-se, dessa forma, que a internacionalização passa a ser considerada como um problema público vinculado ao desenvolvimento econômico dos países, integrando-se ao ciclo de políticas públicas.

Com objetivo de facilitar essa interpretação, sugeriu-se no presente ensaio a constituição de um referencial teórico com vistas a se tornar um framework de identificação e análise das dimensões das políticas governamentais direcionadas à internacionalização. Desse modo, elaborou-se um escopo de análise de seus instrumentos mais típicos, que permite considerá-las como uma política específica e direcionada, avultando em seu fulcro a internacionalização como seu problema-chave. Assim, a partir da identificação de que as primeiras políticas para estes fins foram as comerciais, analisou-se a evolução de seus instrumentos nos últimos anos, chegando-se a um escopo comum que pudesse ser considerado de apoio à internacionalização, o qual, por meio de seis dimensões propostas, abarca todas as modalidades e direções dos negócios internacionais. Pretendeu-se, com isso, que esse framework seja utilizado em pesquisas futuras, com alguns objetivos claros com relação à descrição e inferência de importantes pontos, os quais podem compor uma agenda de reflexão: i) identificar em quais países a internacionalização já é tratada como um problema público; ii) permitir, por meio das dimensões propostas, realizar análise cross-national que possibilite, como sugeriu Fonseca (2013), ter seu conteúdo adaptado aos contextos nacionais, respeitando as suas peculiaridades, uma vez que tal problema e política não são one-size-fits-all; iii) inferir, estatisticamente, seu impacto na internacionalização das empresas nacionais, podendo tais políticas serem consideradas ou não, nos países em que se trata de uma opção, de uma vantagem de localização internalizadas pelas empresas nacionais; iv) observar como seu ciclo ocorre, especificamente o papel de atores não-estatais, dado se tratar de uma política normalmente alinhada com as características micro e mesoeconômicas das empresas e de seus setores, não sendo de formulação linear, além de suscetível a efeito de captura do governo pelos privados. 


\section{REFERÊNCIAS}

ABREU, M. P. Política comercial brasileira: limites e oportunidades. In: PINHEIRO, A. C.; MARKWALD, R.; PEREIRA, L. V. (Org.). O desafio das exportações. Rio de Janeiro: BNDES, 2002. 29-49 p.

ACYOLI, L.; LIMA, L. A. F.; RIBEIRO, E. (Org.). Internacionalização de empresas: experiências internacionais selecionadas. Brasília, DF: Ipea, 2011.

AGÊNCIA BRASILEIRA DE PROMOÇÃO DAS EXPORTAÇÕES E DOS INVESTIMENTOS - APEX-BRASIL, 2013. Disponível em: <http://www. apexbrasil.com.br>. Acessado em: 4 nov. 2013.

AIGINGER, K. Industrial policy: a dying breed or a re-emerging phoenix. Journal of Industrial, Competition and Trade, v. 7, p. 297-323, 2007.

ALBUQUERQUE, V. Política de comércio exterior: epicentros e epifenômenos do desempenho exportador das empresas brasileiras. Tese (Doutorado em Administração) - Fundação Getulio Vargas, Rio de Janeiro, 2008.

ALÉM, A. C.; CAVALCANTI, C. E. O BNDES e o apoio à internacionalização de empresas brasileiras: algumas reflexões. Revista do BNDES, v. 12, n. 24, p. 43-76, 2005.

ALÉM; A. C.; MADEIRA, R. Internacionalização e competitividade: a importância da criação de empresas multinacionais brasileiras. In: ALÉM; A. C.; GIAMBIAGI, F. (Org.). O BNDES em um Brasil em transição. Rio de Janeiro: BNDES, 2010. 39-56 p.

ALVAREZ, R. B. P. Instrumentos públicos de incentivo às exportações e o desempenho de estreantes no mercado internacional. Dissertação (Mestrado em Economia Aplicada) - Universidade de São Paulo, Ribeirão Preto, 2013.

BAILEY, D.; LENIHAN, H.; SINGH, A. Lessons for African economies from Irish and East Asian industrial policy. Journal of Industrial, Competition and Trade, v. 9, p. 357-382, 2009.

BARRAL, W. Prefácio. In: ACYOLI, L.; LIMA, L. A. F.; RIBEIRO, E. (Org.). Internacionalização de empresas: experiências internacionais selecionadas. Brasília, DF: Ipea, 2011. 9-10 p.

BAZUCHI, K. R. V. et al. The role of home country political resources for Brazilian multinational companies. Brazilian Administration Review, v. 10, n. 4, p. 415-438, 2013.

BHAUMIK, S. K.; DRIFFIELD, N.; PAL, S. Does ownership structure of emerging-market firms affect their outward FDI? The case of the Indian automotive and pharmaceutical sectors. Journal of International Business Studies, v. 41, n. 3, p. 437-450, 2010.

BODDEWYN, J. J. Political behavior research. In: BUCKLEY, P. J. (Ed.). New directions in international business. Cheltenham: Edward Elgar, 1992. 81-87 $p$.

BRASIL. Brasil Maior: Plano 2011/2014. Texto de referência. 2011. Disponível em: <http://www.brasilmaior.mdic.gov.br/wp-content/ uploads/2011/11/plano_brasil_maior_texto_de_referencia_rev_ out11.pdf>. Acessado em: 2 jan. 2014.

BRESSER-PEREIRA, L. C. Globalização e competição: por que alguns países emergentes têm sucesso e outros não. Rio de Janeiro: Elsevier, 2009.
BUCKLEY, P. J. Government policy responses to strategic rent-seeking transnational firms. In: BUCKLEY, P. J. International strategic management and government policy. New York: St. Martin's Press, 1998. 7-24 p.

BUCKLEY, P. J. Is the international business research agenda running out steam? Journal of International Business Studies, v. 33, n. 2, p. 365-373, 2002.

BUCKLEY, P. J.; CASSON, M. The future of the multinational enterprise: $25^{\text {th }}$ anniversary edition. 2. ed. New York: Palgrave Macmillan, 2002.

CÂMARA DE COMÉRCIO EXTERIOR - CAMEX et al. Termo de referência: internacionalização de empresas brasileiras. 2009. Disponível em: <http://www.mdic.gov.br/arquivos/dwnl_1260377495.pdf>. Acessado em: 5 jan. 2014.

CAMILO, S. P. O.; MARCON, R.; BANDEIRA-DE-MELLO, R. Conexões políticas das firmas e seus efeitos na performance: uma convergência entre as perspectivas da governança e da dependência de recursos. Revista Alcance, v. 19, p. 241-258, 2012.

CARNOY, M. et al. Introduction. In: CARNOY, M. et al. The new global economy in the information age: reflections on our changing world. University Park, PA: Pennsylvania State University Press, 1996. 1-14 p.

CASTELLS, M. A sociedade em rede. 2. ed. São Paulo: Paz e Terra, 1999.

CAVES, R. E. Multinational enterprises and economic analysis. 2. ed. New York: Cambridge University Press, 1996.

CAVUSGIL, S. T.; CZINKOTA, M. R. (Eds.). International perspectives on trade promotion and assistance. New York: Quorum Books, 1990a.

CAVUSGIL, S. T.; CZINKOTA, M. R. Preface. In: CAVUSGIL, S. T.; CZINKOTA, M. R. (Eds.). International perspectives on trade promotion and assistance. New York: Quorum Books, 1990b. XVII-XVIII p.

CAVUSGIL, S. T.; YEOH, P.-L. Public sector promotion of U.S. export activity: a review and directions for the future. Journal of Public Policy \& Marketing, v. 13, n. 1, p. 76-84, 1994.

CHANDLER, JR., A. D. Strategy and structure: chapters in the history of the industrial enterprise. Cambridge, MA: The MIT Press, 2001.

CHILD, J.; RODRIGUES, S. B. The internationalization of Chinese firms: a case of theoretical extension? Management and Organization Review, v. 1, n. 3, p. 381-418, 2005

COELHO, D. B.; ROCHA, C. P. Estratégia e gestão em agências de promoção das exportações e investimentos: o caso UK Trade \& Investment no Brasil. Globalization, Competitiveness \& Governability, v. 7, n. 2, p. 68-84, 2013.

COLUCHI, A. A. R. M. Promoção das exportações brasileiras: avaliação de desempenho. 106 f. Dissertação (Mestrado em Administração) - Universidade de São Paulo, São Paulo, 2011.

CZINKOTA, M. R. A national export assistance policy for new and growing business. Journal of International Marketing, v. 2, n. 1, p. 91-101, 1994

DEPARTAMENTO DE TAQUIGRAFIA DA CÂMARA DOS DEPUTADOS DETAQ-CD. Discurso e notas taquigráficas de Sr. Nelson Marchezan Junior. Sessão 245.1.54.0, 15 set. 2011. 
DIAMANTOPOULOS, A.; SCHLEGELMILCH, B. B.; KATY TSE, K. Y. Understanding the role of export marketing assistance: empirical evidence and research needs. European Journal of Marketing, v. 27, n. 4, p. 5-18, 1993.

DICKEN, P. Mudança global: mapeando as novas fronteiras da economia mundial. 5. ed. Porto Alegre: Bookman, 2010.

DUNNING, J. H. Business analytic approach to governments and globalization. In: DUNNING, J. H. (Ed.). Governments, globalization, and international business. Oxford: Oxford University Press, 1997. 114-131 p.

DUNNING, J. H. An overview of relations with national governments. New Political Economy, v. 3, n. 2, p. 280-284, 1998.

DUNNING, J. H.; LUNDAN, S. M. Multinational enterprises and the global economy. 2. ed. Cheltenham: Edward Elgar, 2008.

FLEURY, A.; FLEURY, M. T. L. Internacionalização de empresas brasileiras: em busca de uma abordagem teórica para os late movers. In: FLEURY, A.; FLEURY, M. T. L. (Orgs.). Internacionalização e os países emergentes. São Paulo: Atlas, 2007. 3-14 p.

FONSECA, F. Dimensões críticas das políticas públicas. Cad. EBAPE. BR, v. 11, n. 3, p. 402-418, 2013.

GILLESPIE, K.; RIDDLE, L. Export promotion organization emergence and development: a call to research. International Marketing Review, v. 21 , n. 4 , p. $462-473,2004$.

GILPIN, R. Global political economy: understanding the international economic order. Princeton, NJ: Princeton University Press, 2001.

GRIMALDI, D. S.; CARNEIRO, F. L. Avaliação de políticas públicas de promoção de exportação: uma análise de microdados para o BNDESExim, Proex e Drawback entre 2003 e 2007. In: ACIOLY, L.; CINTRA, M. A. M. Inserção internacional brasileira: temas de economia internacional. Brasília, DF: Ipea, 2010. 481-512 p.

GROSSE, E. Introduction. In: GROSSE, E. (Ed.). International business and government relations in the 21st century. Cambridge, MA Cambridge University Press, 2005. 1-22 p.

GUEDES, A. L. Internacionalização de empresas como política de desenvolvimento: uma abordagem de diplomacia triangular. Rev. Adm. Pública, v. 40, n. 3, p. 335-356, 2006.

HAM, C.; HILL, M. The policy process in the modern capitalism State. New York: Harvest, 1984.

HEIDEMANN, F. G. Do sonho do progresso às políticas de desenvolvimento. In: HEIDEMANN, F. G.; SALM, J. F. (Org.). Políticas públicas e desenvolvimento. Brasília, DF: Ed. UnB, 2009. 23-40 p.

HENNART, J.-F. Emerging market multinationals and the theory of the multinational enterprise. Global Strategy Journal, v. 2, n. 1, p. 168-187, 2012.

HILLMAN, A.; HITT, M. A. Corporate political strategy formulation: a model of approach, participation, and strategy decisions. Academy of Management Review, v. 24, n. 4, p. 825-842, 1999.

HILLMAN, A.; KEIM, G.; SCHULER, D. Corporate political activity: a review and research agenda. Journal of Management, v. 30, n. 6, p. 873-857, 2004.
HOWLETT, M.; RAMESH, M.; PERL, A. Política pública: seus ciclos e subsistemas - uma abordagem integral. Rio de Janeiro: Campus, 2013.

HYMER, S. Empresas multinacionais: a internacionalização do capital. 2. ed. Rio de Janeiro: Graal, 1983.

ILHA, F. Convite para seminário que sugere produção no exterior constrange setor calçadista gaúcho. Jornal Zero Hora, 15 set. 2011.

INSTITUTO DE ESTUDOS PARA O DESENVOLVIMENTO INDUSTRIAL IEDI. Internacionalização de empresas brasileiras e a nova lei de tributação de lucros no exterior. 2013. Disponível em: <http://www.iedi. org.br/cartas/carta_iedi_n_591.html>. Acessado em: 26 dez. 2013.

INSTITUTO DE PESQUISAS ECONÔMICAS APLICADAS - IPEA. Internacionalização de empresas: experiências internacionais selecionadas. Comunicados do Ipea, n. 150, Brasília, DF: 2012.

JARAMILLO, C. The basic functions of national trade promotion organization. International Trade Forum, n. 3, 1992.

KELLY, P. F. The geographies and politics of globalization. Progress in Human Geography, n. 23, p. 379-400, 1999.

KINGDON, J. W. Agendas, alternatives, and public policies. New York: Harper Collins, 2003.

KOTABE, M.; CZINKOTA, M. R. State government promotion of manufacturing exports: a gap analysis. Journal of International Business Studies, v. 23, n. 4, p. 637-658, 1992.

KUMPE, T.; BOLWIJN, P. T. Toward the innovative firm: challenge for research and development management. Research Technology Management, v. 37, n. 1, p. 38-44, 1994.

LEDERMAN, D.; OLARREGA, M.; PAYTON, L. Export promotion agencies: what works and what doesn't. World Bank Policy Research Working Paper, n. 4.044, 2006.

LEMOS, F. L. A political view on the internationalization process. Dissertação (Doutorado em Filosofia) - Uppsala University, Uppsala, 2013.

LEVY, P. M.; NONNENBERG, M. J. B.; COSTA, K. P. O desenvolvimento da China e da Índia: lições e implicações para o Brasil. In: BARROS, O.; GIAMBIAGI, F. (Org.). Brasil globalizado: o Brasil em um mundo surpreendente. Rio de Janeiro: Elsevier, 2008. 158-196 p.

LEWIS, R. J. Foreword. In: CAVUSGIL, S. T.; CZINKOTA, M. R. (Eds.). International perspectives on trade promotion and assistance. New York: Quorum Books, 1990. 12-14 p.

LUO, Y.; TUNG, R. L. International expansion of emerging markets enterprises: a springboard perspective. Journal of International Business Studies, v. 38, n. 4, p. 481-198, 2007.

MAJOCCHI, A.; BACCHIOCCHI, E.; MAYRHOFER, U. Firm size, business experience and export intensity in SMEs: a longitudinal approach to complex relationship. International Business Review, v. 14, n. 6, p. 719-738, 2005.

MALHOTRA, N.; HINNINGS, C. R. B. An organizational model for understanding internationalization processes. Journal of International Business Studies, v. 41, n. 2, p. 330-349, 2010.

MARKWALD, R.; PUGA, F. P. Focando a política de promoção de exportações. In: PINHEIRO, A. C.; MARKWALD, R.; PEREIRA, L. V. (Org.). $O$ desafio das exportações. Rio de Janeiro: BNDES, 2002. 49-154 p. 
MUSACCHIO, A.; LAZZARINI, S. G. Leviathan in business: varieties of State capitalism and their implications for economic performance, 2013. Disponível em: $<$ http://ssrn.com/abstract=2070942>. Acessado em: 1 fev. 2014

NAGEL, S. S. Handbook of public policy evaluation. Thousand Oaks: Sage, 2002.

NOLAN, P. China and the global economy: national champions, industrial policy, and the big business revolution. New York: Palgrave, 2001.

OHMAE, K. The borderless world: power and strategy in the interlinked economy. Nova York: Free Press, 1990.

PACK, H.; SAGGI, K. The case for industrial policy: a critical survey. World Bank Policy Research Working Paper Series, n. 3.839. Disponível em: <http://www-wds.worldbank.org/servlet/WDSContentServer / WDSP/IB/ 2006/01/31 /000016406_20060131160754/Rendered/ PDF/wps3839.pdf>. Acessado em: 29 set. 2013.

PENROSE, E. T. A teoria do crescimento da firma. Campinas, SP: Unicamp, 2006.

PIANTO, D. M.; CHANG, L. O potencial exportador e as políticas de promoção das exportações da Apex-Brasil. In: DE NEGRI, J. A.; ARAÚJO, B. C. P. (Org.). As empresas brasileiras e o comércio internacional. Brasília, DF: Ipea, 2007. 87-108 p.

PORTER, M. E. A vantagem competitiva das nações. 14. ed. Rio de Janeiro: Elsevier, 1989.

PORTER, M. E. Introduction and summary. In: PORTER, M. E. (Ed.). Competition in global industries. Boston, MA: Harvard Business School Press, 1986. 1-14 p.

RAMAMURTI, R. What is really different about emerging market multinationals? Global Strategy Journal, v. 2, n. 1, p. 41-47, 2012.

RICUPERO, R.; BARRETO, F. M. A importância do investimento direto estrangeiro do Brasil no exterior para o desenvolvimento socioeconômico do país. In: ALMEIDA, A. (Org.). Internacionalização de empresas brasileiras: perspectivas e riscos. Rio de Janeiro: Elsevier, 2007. 1-36 p.

ROCHA, A.; ALMEIDA, V. Estratégia de entrada e de operações em mercados internacionais. In: TANURE, B.; DUARTE, R. G. (Org.). Gestão internacional. São Paulo: Saraiva, 2006. 7-37 p.

RODRIK, D. Industrial policy for the twenty-first century. 2004 Disponível em: <http://www.hks.harvard.edu/fs/drodrik/Research\%20 papers/UNIDOSep.pdf>. Acessado em: 4 jun. 2012.

RUBIO, F. C. A ortodoxia e heterodoxia revista em sua base: uma leitura de economia política. $88 \mathrm{f}$. Dissertação (Mestrado em Economia) - Fundação Getulio Vargas, São Paulo, 2012.

SALLY, R. Multinational enterprises, political economy an institutional theory: domestic embeddedness in the contexto of internationalization. Review of International Political Economy, v. 1, n. 1, p. 161-192, 1994.

SALLY, R. States and firms: multinational enterprises in institutional competition. New York: Routledge, 2000.

SBRAGIA, R. et al. Inovação: como vencer esse desafio empresarial. São Paulo: Clio, 2006.
SCHMIDT, F. H.; SILVA, J. F. Apoio à exportação: evidências empíricas e desafios para futuras pesquisas. Texto para Discussão Ipea, $n$. 1785. Brasília, DF: Ipea, 2012.

SCHULER, D.; REHBEIN, K.; CRAMER, R. Pursuing strategic advantage through political means: a multivariate approach. Academy of Management Journal, v. 45, n. 4, p. 659-672, 2002.

SECCHI, L. Políticas públicas: conceitos, esquema de análise, casos práticos. São Paulo: Cengage Learning, 2013.

SENNES, R.; MENDES, R. C. Políticas públicas e as multinacionais brasileiras. In: RAMSEY, J.; ALMEIDA, A. (Org.). A ascensão das multinacionais brasileiras: $o$ grande salto de peso-pesados regionais a verdadeiras multinacionais. Rio de Janeiro: Elsevier, 2009. 157-174 p.

SERINGHAUS, F. H. R. The impact of government export marketing assistance. International Marketing Review, v. 3, n. 2, p. 55-66, 1986.

SERINGHAUS, F. H. R.; BOTSCHEN, G. Cross-national comparison of export promotion services: the views of Canadian and Austrian companies. Journal of International Business Studies, v. 22, n. 1, p. 115-133, 1991.

SINGER, T. O. The role of export promotion in export management: the case of the Minnesota trade office. Washington, DC: George Washington University, 1990.

SOETE, L. From industrial to innovation policy. Journal of Industrial, Competition and Trade, v. 7, p. 273-284, 2007.

SOUSA, F. F.; LEMOS, F. F. Complexity and independency in firm's internationalization: when the state become the partner. International Journal of Business Environment, v. 4, n. 2, p. 485-504, 2009.

SOUZA, C. Políticas públicas: uma revisão de literatura. Sociologias, v. 8 , n. 16, p. 20-45, 2006.

STOPFORD, J. M. The growing interdependence between transnational corporations and governments. In: BUCKLEY, P. J.; GHAURI, P. (Eds.). The global challenge for multinational enterprises: managing increasing interdependence. Oxford: Elsevier Science, 1999. 382-403 p.

STOPFORD, J. M. Implications for national governments. In: DUNNING, J. H. (Ed.). Governments, globalization, and international business. Oxford: Oxford University Press, 2003. 457-480 p.

STOPFORD, J.; STRANGE, S.; HENLEY, J. S. Rival states, rival firms: competition for world market shares. Cambridge, MA: Cambridge University Press, 1991.

STRANGE, S. States and markets. 2. ed. London: Pinter, 1994.

STRANGE, S. States, firms, and diplomacy. In: FRIEDEN, J. A.; LAKE, D. A. (Eds.). International political economy: perspectives in global power wealth. 4. ed. Boston, MA: Routledge, 2000. 60-68 p.

SUZIGAN, W.; FURTADO, J. Política industrial e desenvolvimento. Revista de Economia Política, v. 26, n. 2, p. 163-185, 2006.

UNITED NATIONS CONFERENCE ON TRADE AND DEVELOPMENT UNCTAD. TNCs and the internationalization of R\&D. World investment report 2005. Geneva: UN, 2005.

UNITED NATIONS CONFERENCE ON TRADE AND DEVELOPMENT UNCTAD. FDI from developing transition economies: implications for development. World investment report 2006. Geneva: UN, 2006. 
UNITED NATIONS CONFERENCE ON TRADE AND DEVELOPMENT UNCTAD. Transnational corporations, and infrastructure challenge. World investment report 2008. Geneva: ONU, 2008.

VALOR. Coutinho sugere consolidação do setor siderúrgico. Jornal Valor Econômico, 22 set. 2009.

VEIGA, P. M.; IGLESIAS, R. M. A institucionalidade da política brasileira de comércio exterior. In: PINHEIRO, A. C.; MARKWALD, R.; PEREIRA, L. V. (Orgs.). O desafio das exportações. Rio de Janeiro: BNDES, 2002. 53-96 p.

VERNON, R. In the hurricane's eye: the troubled prospects of multinational enterprises. Boston, MA: Harvard University Press, 1998.
VIETOR, R. H. K. How countries compete: strategy, structure, and government in the global economy. Boston, MA: HBS Press, 2007.

WANG, C. et al. Exploring the role of government involvement in outward FDI from emerging countries. Journal of International Business, v. 43, p. 655-676, 2012.

WILLIAMSON, O. E. Mercados y jerarquías: su análisis y su implicaciones antitrust. México, DF: Fondo de Cultura Económica, 1991.

YEUNG, H. W. Capital, state and space: contesting the borderless world. Transactions of the Institute of British Geographers, v. 23, n. 3, p. 291-309, 1998.

Diego Bonaldo Coelho

Doutor em Administração pela Universidade de São Paulo (USP); Professor de Relações Internacionais da Escola Superior de Propaganda e Marketing (ESPM) e do Departamento de Economia da Faculdade de Economia, Administração, Contábeis e Atuariais da Pontifícia Universidade Católica de São Paulo (FEA/PUC-SP).E-mail: diego.coelho@espm.br

Moacir de Miranda Oliveira Junior

Doutor em Administração pela Universidade de São Paulo (USP); Professor Associado do Departamento de Administração da Faculdade de Economia, Administração e Contabilidade da Universidade de São Paulo (FEA-USP). E-mail: mirandaoliveira@usp.br 